\title{
Transaction Cost Economics: An Assessment of Empirical Research in the Social Sciences
}

\author{
Jeffrey T. Macher ${ }^{*}$ \\ Robert E. McDonough School of Business \\ Georgetown University \\ itm4@georgetown.edu \\ and \\ Barak D. Richman \\ Duke University School of Law \\ Duke University \\ richman@law.duke.edu
}

\begin{abstract}
This paper provides a comprehensive review of the empirical literature in transaction cost economics (TCE) across multiple social science disciplines and business fields. We show how TCE has branched out from its economic roots to examine empirical phenomena in several other areas. We find TCE is increasingly being applied not only to business-related fields such as accounting, finance, marketing, and organizational theory, but also to areas outside of business including political science, law, public policy, and agriculture and health. With few exceptions, however, the use of TCE reasoning to inform empirical research in these areas is piecemeal. We find that there is considerable support of many of the central tenets of TCE, but we also observe a number of lingering theoretical and empirical issues that need to be addressed. We conclude by discussing the implications of these issues and outlining directions for future theoretical and empirical work.
\end{abstract}

\footnotetext{
* We thank Erin Anderson, Christopher Boerner, Scott Masten, Jackson Nickerson, Brian Silverman and especially Oliver Williamson for valuable comments and suggestions. Additional thanks go to Mark Marvelli and Nataliya Kuribko for excellent research assistance. The authors are solely responsible for any errors and omissions, though they ask readers to understand that omissions will be inevitable.
} 


\section{INTRODUCTION}

In his presidential address to the Royal Economic Society in 1986, R. C. O. Matthews noted, "the economics of institutions has become one of the liveliest areas in our discipline" (Matthews 1986: 903), and recognized that the study of economic institutions turned on two propositions: first, "institutions do matter"; and second, "the determinants of institutions are susceptible to analysis by the tools of economic theory” (1986: 903). This assessment was based principally on the accomplishments of transaction cost economics (TCE) through the mid-1980s. There have been substantial theoretical and, especially, empirical developments in the twenty years since. ${ }^{1}$ As Williamson notes, the initial skepticism that surrounded this theory has given way to respect earned "not by advancing an overarching theory but by uncovering and explicating microanalytic features and by piling block upon block until the cumulative value added cannot be denied” (2000: 596). This growing acceptance is partly the result of a significant body of empirical research in economics that is largely consistent with TCE predictions.

Several reviews, most notably Joskow (1988) and Shelanski and Klein (1995), ${ }^{2}$ have highlighted the increasing number of corroborative empirical papers that have appeared in economics journals since the development of the theory by Williamson (1975; 1979), Klein, Crawford and Alchian (1978) and more formally by Grossman and Hart (1986) and Hart and Moore (1990). While these surveys largely attest to the empirical success of transaction cost economics in Industrial Organization (IO) economics, far less is known about the influence of TCE within other business-related areas. ${ }^{3}$ Furthermore, the empirical applications of TCE to other fields further removed from IO economics, including law and political science, public policy, health economics and policy and agricultural economics and policy, have not been systematically explored.

In this survey we attempt to address these issues on several fronts: first, by providing a comprehensive picture of the existing empirical TCE literature both within economics and in 
other social science areas; second, by assessing the implications of this literature for transaction cost theory; and third, and perhaps most importantly but more modestly, by shaping the direction of future empirical work. To these ends, the paper presents the results of an extensive literature review in which numerous on-line and hardbound sources were examined for articles that utilize transaction cost economics and have a significant empirical component. This exercise generated over 3,500 abstracts from which we obtained approximately 900 articles that empirically test some aspect of TCE theory. ${ }^{4}$ We then categorized these articles by field of interest (e.g. economics, law, political science, etc.). Recognizing that any attempts to associate knowledge by disciplinary fields are somewhat arbitrary, we utilized all available information, notably the subject headings, author affiliation, JEL key words and publishing journal, for the purposes of categorization. The result is a two-tiered approach in which each article is first classified as being business related or non-business related and then placed within its most appropriate field (i.e., for business, economics, marketing, finance, etc.; for non-business, law, political science, etc.). While imperfect, we believe this taxonomy is an accurate classification scheme that provides better understanding of the empirical contexts to which transaction cost economic logic has been applied and more accurately assesses the implications of transaction cost economics broad research approach.

The rest of the paper is organized as follows. The next section provides a brief theoretical and empirical overview of transaction cost economics. Section 3 outlines the methodology that we employ in the literature review and then summarizes its main findings. Section 4 reviews the main empirical findings of transaction cost economic theory in a number of different areas of study. Section 5 provides a critical assessment of these findings, highlighting the progress that has been made but denoting the gaps in the theory and empirical analysis that still remain. Section 6 provides a summary and conclusion. 


\section{THEORETICAL AND EMPIRICAL PRELIMINARIES}

\subsection{THEORETICAL BACKGROUND}

Because recent theoretical statements of the approach of transaction cost economics

(TCE) to the study of economic organization can be found elsewhere (Williamson 1998; 2000), we provide a compact version here. The key conceptual move to TCE is to describe firms not in neoclassical terms (as production functions) but in organizational terms (as governance structures). The basic insight of TCE is to recognize that in a world of positive transaction costs, exchange agreements must be governed, and that, contingent on the transactions to be organized, some forms of governance are better than others.

There are at least three main factors underlying positive transaction costs. First, individuals are limited in their ability to plan for the future and in spite of their best efforts to deal with the complexity and unpredictability of the world around them, they lack the knowledge, foresight and/or skill to accurately predict and plan for all the various contingencies that may arise (Simon 1957). Second, even if perfect planning were possible, it is hard for contracting parties to negotiate about these plans due to the difficulty associated with developing a common language to describe actions and states of the world with which the parties have little prior experience (Hart 1995). Third, assuming that parties could plan and negotiate for a fully contingent contract, it frequently remains difficult for them to communicate their plans in such a way that an uninformed third-party (e.g., a court) could reasonably enforce them. The upshot is that all contracts are actually and effectively incomplete. ${ }^{5}$

One economic implication of contractual incompleteness is that when circumstances arise that were not accounted for in the original agreement, parties must partake in costly renegotiations and may engage in excessive haggling over how to revise the contractual terms. Particularly problematic are calculated efforts on the part of individuals to mislead, renege, cheat or otherwise take advantage of the vulnerabilities of their trading partners in hopes of achieving a more favorable distribution of the rents accruing to exchange. Although not everyone is so 
inclined, the bounded rationality conditions outlined above make it difficult to uncover untrustworthy individuals ex ante (Williamson 1996).

To safeguard against such opportunistic behavior, parties select institutional arrangements so as to mitigate the expected total cost of consummating the transactions involved. The governance structures that firms employ to guard against these contracting hazards vary in discrete structural ways with reference to their adaptive performance by reasons of differences in incentive intensity, administrative controls and contract law regime (Williamson 1991). ${ }^{6}$ Market forms of organization rely on prices to signal opportunities for autonomous adaptation to changing conditions in order to exploit new profit opportunities. As specialized or relationship specific investments increase, coordinated adaptation becomes more important. The movement from market to hierarchy entails trading off high-powered incentives and autonomous adaptive properties for the added safeguards and centralized coordinating properties of internal organization. ${ }^{7}$ Different governance forms, such as markets, hybrids, firms and bureaus, etc., are never examined alone but always in relation to one another. Identifying and explicating the syndromes of attributes that define each generic mode of governance are central to the exercise.

The transaction is named as the basic unit of analysis and the critical dimensions to which transactions differ are also identified and the ramifications worked out. The logic of discriminating alignment-according to which "transactions, which differ in their attributes, are aligned with governance structures, which differ in their cost and competence, so as to effect a transaction cost economizing result” (Williamson 1991: 79)—is then employed to derive refutable implications. A final assumption underlying transaction cost economics is that important dimensions along which transactions differ can be identified and measured, ${ }^{8}$ qualitatively if not quantitatively.

The idea that governance is a means by which to induce order, thereby to mitigate conflict and realize mutual gain is a recurrent theme (Williamson 2000). The basic regularity is this: complex modes of organization are reserved for complex transactions, to which contractual 
hazards accrue; whereas simple modes of governance suffice for simple transactions, of which the ideal transactions in both law and economies are those for which identity does not matter. To use a simple mode of governance to manage a complex transaction would be to risk contractual breakdown, whereas to use a complex mode of governance to manage a simple transaction would be to incur costs without gain.

\subsection{EMPIRICAL OPERATIONALIZATION}

The majority of empirical research in transaction cost economics is a variation of the discriminating alignment hypothesis (Williamson 1979; 1991) identified above. Organizational mode is the dependent variable, while transactional properties, as well as other control variables, serve as independent variables. The most common empirical approach is to conceptualize organizational form as one of three broad discrete types: market, hierarchy, or various hybrid and intermediate modes. ${ }^{9}$ Hybrid modes of governance include joint ventures (Klein, Frazer et al. 1990), relational contracting (Palay 1984), and bilateral governance (Heide and John 1990). Oxley (1999) in particular examines the proliferation of different governance modes in alliances, creating a market-hierarchy spectrum that ranges from unilateral contractual agreements (e.g., one-sided licensing agreements, long-term supply contracts and R\&D contracts), to bilateral contractual agreements (e.g., technology sharing or cross-licensing agreements, joint research agreements) to equity-based alliances (i.e., joint ventures).

The probability of observing more (less) integrated forms of organization depends upon the underlying properties of the transaction. More integrated governance modes are associated with a higher degree of relationship-specific assets, greater uncertainty (including but not limited to customer, supplier or technological uncertainty), more complex transactions, or more frequent exchange. Of the transactional properties that have been examined empirically, asset specificity, or the transferability of assets that support a given transaction to a different use or different user, is argued to be the most important (Williamson 1985) and has subsequently seen the most proliferations in the empirical literature. Measures of asset specificity in empirical TCE research 
are broad, ${ }^{10}$ often subjective (Minkler and Park 1994), and include the physical proximity (i.e., site specificity) between contracting parties (Joskow 1985; 1987; 1990), idiosyncratic investments (Palay 1984), product complexity (Masten 1984), inter-firm co-specialization (Dyer 1996), and spatial or temporal proximity (Masten, Meehan et al. 1991; Pirrong 1993). A large number of empirical studies have examined specific investments associated with human capital. These studies are prevalent not only because human capital represents a significant cost of doing business, but also because there are a wide variety of measurement approaches. Examples of human capital measurement include the specificity of developing automotive components for a vehicle assembler (Monteverde and Teece 1982a; 1982b), the specificity of the working relationship between a salesperson and his or her organization (Anderson 1985), the specificity of communication between product designers and manufacturing engineers in the semiconductor industry (Monteverde 1995), and as far reaching as the specificity of the wife to the household and the use of prenuptial contracts (Hamilton 1999) and the specificity of individual rock band members - measured in terms of ease of member replacement — to critics' assessments of music quality (Cameron and Collins 1997). ${ }^{11}$

The treatment of uncertainty in the empirical TCE literature is similarly broad, but more uneven in comparison to asset specificity’s treatment. Transactional uncertainty generally refers to "unanticipated changes in circumstances surrounding an exchange”(Noordewier, John et al. 1990: 82), and is typically in reference to changes in the environment to future events (Anderson 1985). A second type of uncertainty has a behavioral foundation but this construct has seen far fewer operationalizations in the literature. Measurements constructs of environmental uncertainty that have been employed in empirical analyses are broad and include demand uncertainty (Heide and John 1990), technological uncertainty (Walker and Weber 1984; Balakrishnan and Wernerfelt 1986) and supplier uncertainty (Walker and Weber 1987), while measurement constructs of behavioral uncertainty often attempt to measure and evaluate partner performance (Anderson 1985; Heide and John 1990; Stump and Heide 1996). Although each uncertainty type is 
concerned with exploring the hazards of maladaptation, empirical findings that relate uncertainty to organizational form are mixed, partly because of the multitude of uncertainty types examined. One potential explanation for the diverse empirical findings around uncertainty is that it needs to be examined in conjunction with asset specificity (Harrigan 1986). Absent asset specificity, TCE does not predict that uncertainty leads to more hierarchical forms of governance. It is only when contractual hazards brought on by relationship specific investment are at risk that expropriation is a concern. Klein (1989) plausibly suggests that different types of uncertainty-with opposite influences on governance mode-are primarily responsible for uncertainty’s empirical inconsistencies. ${ }^{12}$ Adding to the difficulties surrounding the treatment of uncertainty in the empirical TCE literature, it is often the case that complexity and uncertainty are used interchangeably, although the two are distinct analytical concepts (Slater and Spencer 2000). Transaction frequency has received far less treatment in the empirical literature in comparison to asset specificity and uncertainty (Rindfleisch and Heide 1997). Williamson notes that higher levels of transaction frequency provide an incentive for internal organization because "the costs of specialized governance structures will be easier to recover for large transactions of a recurring kind” (1985:60). If, however, reputation effects work well, increasing transactional frequency will support stronger reputation effects (Williamson 2001). Despite the proposed advantage of internal organization in realizing scale economies related to transaction frequency researchers have been largely unsuccessful confirming this hypothesis. Several empirical studies show no positive association between transaction frequency and organizational mode (Anderson and Schmittlein 1984; Anderson 1985; Maltz 1993; 1994), while other studies dichotomize transaction frequency into one-time versus recurring exchanges and do find a significant relationship (John and Weitz 1988; Klein, Frazer et al. 1990). Greater theoretical and empirical treatment on unpacking uncertainty is therefore required by researchers. 


\subsection{EMPIRICAL SPECIFICATION}

Empirical research in transaction cost economics employs a variety of econometric and historical methods. In the same approach as Shelanski and Klein (1995), we define "empirical” broadly to include qualitative case studies, quantitative single-industry studies, and crosssectional econometric analyses. Although case studies are often criticized because of their lack of generality and possible ex-post rationalization, they are an important and necessary complement to econometric analysis (Masten and Saussier 2000) and often provide a richer description and perspective than many statistical analyses offer. These research methods also often represent the stimulus to refinements of transaction cost theory or future quantitative examinations. ${ }^{13}$ By single-industry studies we mean quantitative case studies, or research that quantitatively examines contracting in a single industry. ${ }^{14}$ There are also a growing number of studies that examine crossindustry issues. ${ }^{15}$ The bulk of the empirical research in transaction cost economics falls into these first three categories.

TCE researchers are increasingly implementing more novel methodological approaches than discrete choice analysis to evaluate the influence of transactional properties, hold-up or small numbers bargaining on the mode of governance and over time. One methodological approach that is becoming increasingly more common in the empirical literature in particular is a two-stage estimation of organization mode and performance. This approach examines the influence of exchange attributes on the performance of different governance structures, but first corrects for the selection bias associated with estimating the effect of organizational mode on performance (Masten 1993). ${ }^{16}$ Another more recent methodological approach in empirical TCE research is panel data estimation. Panel data techniques are provocative because they allow researchers to not only control for unobserved heterogeneity, but also improve estimations and test hypotheses that are impossible to examine in cross-sectional analyses. Gonzalez-Diaz et al.’s (2000) examination of subcontracting decisions in the construction industry is an example of the benefits of the panel estimation approach, as is Ohanian's (1994) estimations of changes in vertical integration in the 
U.S. pulp and paper industry over time. Other examples of novel methodological approaches include Park and Russo’s (1996) event history analysis of joint venture failure in the electronics industry, Silverman et al.’s (1997) joint exponential hazard rate event-history and logistic regression analysis of transactional alignment and organizational mortality in the U.S. trucking industry and Ngwenyama and Bryson’s (1999) simulation of the IT outsourcing decision.

\subsection{DATA COLLECTION}

The most common means of primary data collection in empirical TCE research are mail surveys, interviews and firm visits. Researchers often use Likert scales, whereby survey participants rate transactional considerations, such as the degree to which an investment is specific to the relationship or to the level of demand or supply uncertainty present in the industry. These data are subject to the general limitations of survey data in that they are based on respondents' stated beliefs rather than non-subjective valuations. Definitional differences and potential subjectivity across survey respondents mean inter-industry comparisons, and sometimes even inter-firm comparisons, are difficult and therefore must be made with caution. Other researchers employ continuous measures of transactional considerations (Balakrishnan and Wernerfelt 1986), although limitations do exist. In particular, it is unlikely that continuous measures, such as research and development intensity or advertising intensity, can distinguish specific investments from durable or generic investments, or can differentiate contractual hazards from firm-specific capabilities, especially across industries (Henisz 2000). Although surveys are the principal and preferred data collection approach, a number of empirical studies utilize secondary data collection techniques. These techniques include published data from diverse sources such as industry trade publications (Lieberman 1991), government data (Levy 1985), newspapers (Osborn and Baughn 1990), or archival data (Anderson and Coughlan 1987). In comparison to survey or questionnaire data, secondary data may offer shorter collection times and larger sample sizes. Other secondary data sources outside of published data are contracts between exchange partners. Usually employed by economists, the examination of actual contracts 
represent an excellent data source for historical and empirical TCE-related research. ${ }^{17}$ TCE research using contract data is diverse and examines the decision to contract (Lyons 1996), to the length of contract duration (Joskow 1987) and contract design. ${ }^{18}$

A more recent data collection approach employs experimental methods, whereby individuals are separated into control groups and manipulated groups and the impact of manipulated factors, in this case transactional measures typically under a role-playing scenario, on perceived transaction costs are examined. Dutta and John (1995) use student subjects to assess the degree to which licensing technology acts as a safeguard against opportunistic behavior between buyers and suppliers. Pilling et al. (1994) similarly use purchasing managers as subjects to examine the effects of different levels of asset specificity, uncertainty and frequency on transaction costs. Similarly, Sutcliffe and Zaheer (1998) make use of a written decision scenario using an experimental methodology in their examination of uncertainty in the transaction environment.

\section{OVERVIEW OF EMPIRICAL RESEARCH}

Transaction cost economics examines a host of problems related to contracting and economic organization by drawing on its interdisciplinary origins in law, economics and organization. A review of citations, articles and abstracts obtained from a variety of on-line and hardbound sources produced approximately 900 empirical transaction cost economic-related articles and book chapters. ${ }^{19}$ Whereas a detailed review of all of these articles is beyond the scope of this paper, an examination of a subset of these articles categorized within several major areas finds, on the whole, strong support for transaction cost economic predictions.

Figure 1 displays the cumulative number and yearly number of empirical TCE-related articles and book chapters published since 1976, respectively. The first empirical paper is Williamson's (1976) analysis of franchise bidding for monopoly cable television franchises that provided a concrete example in which researchers could examine issues related to contracting. 
Goldberg's (1976) follow-on theoretical analysis of relational contracting and public utility regulation, as well as Klein, Crawford and Alchian’s (1978) examination of relationship-specific investments and incomplete contracts and Williamson's (1979) development of the transactional dimensions that influence cost-minimizing governance structures, provided researchers with the rudiments of a testable theory in which to make governance mode predictions. From these seminal articles, researchers went about finding and measuring variations in governance structure and then matching governance choice to different transactional properties, including asset specificity, uncertainty and complexity.

This is not to say that the theory was completely developed by the early 1980s. Joskow (1988) in particular notes that a rigorous mathematical foundation was missing at this time. Implicit, but underdeveloped, reliance was also placed upon internal organization over markets for resolving disputes. Joskow nevertheless observed that "this body of research had moved us from a general understanding of the importance of transaction costs in explaining the choice between firms and markets and issues associated with the internal organization of the firm, to a fairly specific theory for explaining the structure of vertical relationships based on variations in the importance of asset specificity, uncertainty, product complexity, and the constraints of repeat purchase activity” (p. 101). Monteverde and Teece (1982a) represents the first systematic effort to examine empirically the role of asset specificity in determining the structure of vertical relationships. Along with Masten (1984) and Anderson and Schmittlein (1985), this paper provided an important start to an empirical examination of the make-versus-buy decision and sparked a robust research tradition by providing a sensible empirical approach to hypothesis testing. Stuckey’s (1983) case study and analysis of the aluminum industry also represented an important contribution to building a solid empirical foundation, as it explained the incidence of vertical integration and joint ventures in this industry to transactional factors such as the dedicated nature of the required investments and the small numbers conditions that prevailed in many primary and intermediate markets. 
Figure 1 about here

Figure 2 shows how the share of business-related and non-business-related articles and book chapters has grown over time according to several defined categories. Although empirical TCE research is still dominated by economics, other business-related areas, most notably marketing, international business and organizational behavior, are increasingly making use of transaction cost reasoning in examinations of empirical phenomena. In addition, researchers in fields farther removed from economics, such as law and policy, are also relying more extensively on transaction cost logic. We therefore examine the empirical research that utilizes TCE within economics, within business fields but outside of economics and outside of business, in more detail below.

Figure 2 about here

\section{EMPIRICAL RESEARCH IN TRANSACTION COSTS ECONOMICS}

In this section, we consider how transaction cost economics has been "operationalized” in several distinct fields of two broad groupings. Sub-section 4.1 examines empirical TCE applications in several business-related fields, including economics, marketing, accounting, finance, organization theory, international business and strategy. Sub-section 4.2 then explores how transaction cost reasoning has been implemented in areas farther removed from business, including law and policy, health economics and policy, and agricultural economics and policy. Within each sub-section, we highlight several empirical papers that apply transaction cost reasoning to problems relevant to that area. Although we do not treat all of the areas in which TCE has been applied nor do we review all of the relevant articles in each area, we do emphasize the types of phenomena examined and the main findings that result. 


\subsection{ECONOMICS AND BUSINESS}

\subsubsection{Economics}

Empirical research that applies transaction cost theory in an economic setting examines whether and when particular contracting practices provide efficiency benefits. A large body of the early empirical work in this area was focused on two phenomena: vertical integration and longterm contracting. Since considerable attention is given to earlier empirical contributions in a number of reviews (Joskow 1988; Shelanski and Klein 1995; Masten and Saussier 2000), our discussion examines more recent research related to these phenomena.

Vertical integration, or the make-versus-buy decision, is regarded as the canonical problem. Central to TCE's explanation as to whether economic agents procure critical inputs and services through internal production or via market transactions is the role of asset specificity. The earliest empirical work focuses on the presence of relationship-specific investments as the critical determinant of the vertical integration decision (Monteverde and Teece 1982a; Anderson and Schmittlein 1984; Masten 1984; Joskow 1985). An important outcome of this research was an appreciation for the various types of specific investments that have organizational consequences. While not exhaustive, six distinct types of asset specificity are prominently featured in empirical TCE applications. ${ }^{20}$

Regardless of type, asset specificity has the effect of placing contracting parties in a bilateral dependency relation, which introduce bargaining problems as contractual parties attempt to appropriate the quasi rents generated from relationship specific investments. Recent scholarship has introduced innovative contexts in which these contracting hazards occur. Cavanaugh (1998), for example, explores bargaining problems in the context of unionized labor, observing that unionized workers acquire property rights over jobs thus can appropriate a portion of the quasi-rents generated from their employer's relationship specific investments in physical plants and equipment. Consequently, Cavanaugh finds that as union density increases, firms exhibit lower profitability, investment, and employee growth. In addition, these deleterious 
effects increase as the degree of asset specificity becomes larger because the assets become more nonredeployable to another user or another use, thus increasing the captured quasi rents. ${ }^{21}$ Another creative application is Hamilton's (1999) examination of how human asset specificity affects prenuptial contracts, which finds that couples signing such contracts tend to choose joint ownership of property when wives are particularly important to the "household enterprise." And Coff (2003) examines quasi-rents created by investments in research and development, finding that as R\&D intensity increases managers of a target firm are more likely to enter into lockup agreements with a preferred buyer.

Other recent papers examine the effects of various types of asset specificity on organization. Monteverde (1995), in an examination of the semiconductor industry, finds that the decision to integrate product design with manufacturing is systematically related to required investments in specific human capital. Ulset (1996) shows that asset specificity, proxied for by sunk costs, significantly affects the decision of Norwegian IT firms to integrate commercial research and development (R\&D) projects. Lyons (1995) finds that specific investments are more influential than scale or scope economies for in-house production over market procurement for the purchasing of inputs in the United Kingdom motor vehicle, electronics and metal processing industries. Both Hubbard (2001) and Nickerson and Silverman (2003) observe that the incidence of relationship-specific investments, transaction costs, and other bargaining difficulties drive carrier ownership and complex contracting in the trucking industry. And Shelanski (2004) carries this analysis inside a multi-divisional firm, finding that where the firm's transaction-specific investment is high, corporate headquarters are more likely to centrally administer transfer pricing between divisions. Other applications include Aubert et al.’s (1996) analysis of outsourcing IT systems, Cameron and Collins’ (1997) discussion of rock bands, and Regan’s (1997) research on the influence of brand name capital investments on vertical integration in the insurance industry. And some authors explore the interaction of asset specificity with other transactional characteristics have been found to affect governance choice. Joshi and Stump (1999), for 
example, show from a survey of firms in three SIC codes that transactional uncertainty and trust enhance the effect of manufacturer asset specificity on joint action.

One interesting historical examination of vertical integration and relationship-specific investment is Bindseil's (1997) analysis of the provision of physical assets to the London and New York Stock Exchanges. A stock exchange represents the contractual arrangement governing its members' self-regulation and the provision of the physical assets needed for efficient trade. For much of the history of the London and New York exchanges, these two functions were performed by separate organizations: a membership association of professional traders with the primary purpose of self-regulation; and an organization providing the building in which the centralized trade took place among members of the professional association. Bindseil explains the historical emergence of a vertically integrated exchange by noting the increasingly specific nature of the physical assets that were required to perform trades and argues that the vertical integration of the professional traders' association into the asset-providing firm became the optimal form of governance.

A large body of empirical TCE research examines long-term contracting, particularly the structure and duration of contractual relationships. ${ }^{22}$ A recent extension is Saussier's (2000) analysis of the duration of contracts between private firms and the French state-owned power utility (EDF) for the transportation and unloading of coal to EDF power plants. Using detailed contract data, Saussier finds that the amount of site, physical and human asset specificity associated with a given transaction, as well as the presence of dedicated assets, significantly increase the duration of EDF coal contracts while greater uncertainty significantly decreases the duration of these contracts. Adler and Scherer's (1999) examination of defense procurement contracts similarly suggests that transaction cost factors, including asset specificity, incompleteness and uncertainty, have a significant influence on the specific type of contract that is employed in a given instance. Dahl and Matson’s (1998) analysis of the U.S. natural gas industry contracts and regulatory action presents similar findings between contract duration and 
specific transaction cost factors. Fisher (2004) studies sale and leaseback contracts and finds that the length of initial leasebacks is shorter when landlords make pursue noncontractible future investments. And Weiss and Kurland (1997) investigate interorganizational relationships, such as distribution channels, and find that the level of specialized investment made by downstream partners influences manufacturers’ decisions to terminate these relationships.

Contractual completeness, in addition to contractual duration, is also an important feature of long-term contracts (Masten and Saussier 2000), and although TCE maintains that all contracts are necessarily incomplete, the degree of specified contingencies can vary significantly. When future events can be well predicted or identified through objective measures that do not involve significant disagreement, for example, parties may use contingent contracts that spell out performance guidelines and benchmarks for adjusting contractual provisions. Where such precision is not feasible but continuity is important, parties craft mechanisms for ex-post adaptation through formulas for administering rewards and punishments and through mechanisms that provide flexible responses to changing conditions. Because it is difficult to define performance standards with any precision due to uncertainty about the future, relational contracts tend to be far less specific and precise than contingent contracts. ${ }^{23}$

A good illustration of research in this area is Libecap and Smith's (1999) analysis of oil and gas operating agreements. A problem associated with the production of crude oil and natural gas stems from the common pool losses that result as firms compete to extract migratory oil and gas from subsurface reservoirs. Because property rights are assigned to subsurface hydrocarbons only upon extraction, firms have an incentive to competitively drill and drain a given field as rapidly as possible, even though such behavior reduces aggregate yield. To protect against these hazards, firms typically employ agreements under which a single firm is designated as the unit operator to develop a reservoir but all the firms share in the net returns. Because these agreements are normally long term, involve many parties, and possess considerable uncertainty about geological and economic conditions, they are subject to numerous contractual hazards. Libecap 
and Smith (1999) find that firms that devise intertemporal incentives to relieve these contracting dilemmas, including single and proportional cost and revenue sharing formulas that cover all areas within the common pool and ensure that parties have no private incentives to vary individual production or investment patterns to the detriment of other firms.

Vertical integration and long-term contracting are but two of the generic forms of organization that are examined through a transaction cost economic lens. Other organizational arrangements, which have been labeled "hybrid" governance structures, occupy a location between the extremes of market exchange and vertical integration. Just as with vertical integration and long-term contracting, the empirical literature on these intermediate arrangements has grown significantly, and among the topics receiving considerable recent attention is the study of strategic alliances and equity joint ventures. Oxley (1997), for example, finds that more hierarchical alliance modes (e.g., joint ventures) are typically favored to market-like modes (e.g., cash prepayments) when appropriability hazards are high due to difficulty in specifying or limiting the scope of the technology underlying the alliance. Oxley (1999) adds institutional environment dimensions to her earlier examination and finds that both transaction-level characteristics and the institutional environment—most notably, the level of intellectual property protection—are also important drivers of governance choice. Other papers exploring the influence of transaction and institutional-level factors on alliance formation include Artz and Brush (2000), Elfenbein and Lerner (2003), Gulati and Singh (1998), Pisano (1990a), Robertson and Gatignon (1998) and Simonin (1999). Sampson (2004), using TCE-consistent governance as an explanatory variable and measuring the cost of “misaligned governance,” finds in a sample of R\&D alliances that alliance governance selected according to transaction cost arguments substantially improves collaborative benefits.

Complex contracting is another such hybrid governance mechanism, and one interesting cross-national analysis of the performance effects of using hybrid contracting is found in Dyer's (1996) comparison of how Japanese and U.S. automakers govern supplier relations. Dyer argues 
that part of the explanation for cross-national performance differences in complex product industries relates to systematic differences in governance along the value chain. ${ }^{24}$ Whereas U.S. firms rely largely on market and hierarchical organizational arrangements in dealing with their suppliers, Japanese firms rely mainly on hybrid forms of governance to manage the high degree of co-specialization-particularly with respect to human assets- that exists between firms. ${ }^{25}$ Hybrid forms realize virtually all of the advantages of hierarchies (e.g., asset co-specialization) without some of the disadvantages (e.g., loss of market discipline and flexibility). Japanese automotive value chains use of hybrid organizational forms are argued to offer the benefits of decentralization and competition without sacrificing economies of scale, coordination and cospecialization of assets and therefore appear to incur lower transaction costs than U.S. automotive value chains. These findings are broadly consistent with TCE's prediction that effectively aligning governance structures with transactions result in efficiency benefits. But contrary to TCE's prediction that greater levels of uncertainty will push firms toward vertical integration, Dyer finds that in a world of increasing technological uncertainty the flexibility provided by hybrids is preferable. Other notable studies of complex contracts that function as hybrid governance include Heide, et al.’s (1998) study of exclusive dealing clauses, Kashlak, et al.’s (1998) examination of reciprocity, Menard's (1996) analysis of hybrid contracting in the French poultry industry, and a substantial body of literature on franchising (Zupan 1989; Kaufman and Lafontaine 1994; Minkler and Park 1994; Bercovitz 1999; Brickley 1999).

Recent scholarship has discovered many other hybrid arrangements, with examples include reciprocity agreements, joint ventures, equity linkages and the use of "hostages” to support exchange. Ahmadjian and Oxley (2006), for example, find that partial equity stakes and volume-based dependence serve to institute hostage exchanges that support Japanese automotive supply relationships, and that equity stakes is preferred to volume-based dependence - a comparatively “less robust” form of hostage exchange - when suppliers are particularly vulnerable to assembler opportunism. And Ziedonis (2004) examines the use of patent portfolios 
as a response to potential hold-up problems in markets for innovation, finding that firms patent more aggressively when ownership rights to external technologies are widely distributed.

Although vertical integration, long-term contracting and hybrid forms of organization have been among the most extensively analyzed issues in the economics literature, TCE has been brought to bear on a host of other economics-related phenomena, including monitoring, informal agreements and franchise contracting. The existing empirical literature indicates that TCE analysis is both flexible and far-reaching. We explore highlights of that literature below.

\subsubsection{Marketing}

Behind IO economics, marketing represents the next largest area of business-related empirical TCE research. One reason for this interest in TCE among marketing researchers is its theoretical focus on contracting and exchange makes it relevant to a host of marketing phenomena (Rindfleisch and Heide 1997). ${ }^{26}$ An area in which marketing scholars exploit TCE reasoning extensively is in the analysis of distribution networks. Whereas a large segment of the economics literature examines the decision of manufacturing firms to integrate backward or laterally into the supply of key inputs and services, marketing scholars examine the decision to forward integrate into distribution. Anderson and Schmittlein (1984) and Anderson (1985) explore the decision of electronics firms to utilize a direct sales force versus manufacturer representatives, and in both examinations behavioral uncertainty and asset specificity have a statistically significant and positive effect on the use of an in-house sales force. John and Weitz's (1988) multi-industry study likewise finds that asset specificity and uncertainty are positively related to firms' degree of forward integration into distribution. Similar results by Weiss and Anderson (1992), Dutta, et al. (1995) and Murray and Kotabe (1999) strongly suggest that the transaction-level factors highlighted in TCE are relevant in the decision of firms to integrate into distribution.

These insights regarding forward integration are applied to foreign market entry decisions in Anderson and Coughlan's (1987) examination of foreign market entry ventures by U.S. 
semiconductor firms. The authors find that asset specificity is positively related to the use of an integrated channel. Similar results are found in Taylor, et al. (1998), Klein, et al. (1990) and Eramilli and Rao (1993), and Rialp, et al. (2002) arrives at analogous results from a large sample of Spanish exporters. An interesting application of transaction cost analysis in this area is Klein and Roth (1993), who find that the level of firm satisfaction with the marketing channel is related to the uncertainty and monitoring aspects of the associated transactions.

In addition to exploring forward integration into distribution and foreign entry mode issues, marketing scholars also examine how various intermediate forms of organization are employed to manage distribution channels. Fein and Anderson (1997) explore the use of geographic and brand restrictions in industrial distribution channels. At least on the surface, geographic limitations appear to contradict the basic logic for using distributors (i.e., to gain high coverage at low cost), while brand restrictions appear to contradict the rationale for customers patronizing distributors (i.e., access to an assortment of brands in one place). Using a transaction cost framework and survey data of manufacturer-distributor relationships, the authors find that brand and territory selectivity tend to appear in tandem, ceteris paribus, and suggest that by each reciprocating the pledge of selectivity, agreements are a means by which manufacturers and distributors can credibly commit to a trading relationship made by the other, helping to balance exposure to opportunism and alleviate sources of instability in the relationship. Buvik and John (2000) also examine intermediate organization forms and find that greater vertical coordination, or the purposive organization of activities and information flows between independent organizations, improves adaptation to high environmental uncertainty when relationship specific investments are modest, but has an opposite effect on adaptation when specific investments are significant. The upside to vertical coordination is better adaptation to environmental uncertainty, but the real downside is the additional opportunities that are presented by environmental uncertainty to haggle, exploit or renegotiate, which becomes increasingly likely when specific investments have been made or are at risk. For similar reasons, Murray (2001) found that rising 
globalization has increased firms’ use of strategic alliances to organize global sourcing networks, even after investing in specific assets. And Buvik \& Reve’s (2001) examination of formal purchasing contracts in industrial purchasing relationships reached the interesting result that increased formalization was more highly associated with the specificity of assets employed by the seller than the buyer. The authors conclude that most industrial purchasing relationships are characterized by asymmetric dependence structures.

Several marketing scholars have also examined relational contracting using a TCE lens. Heide and John (1992) examine the effect of relational norms on the level of vertical control in buyer-supplier relations. Although traditional treatments of TCE generally predict a positive relationship between the presence of relationship specific assets and the presence of safeguards for the investing party, the authors instead suggest that the presence of relational norms, including flexibility, information exchange and solidarity, may instead allow one party to cede control and still be protected from relational abuses. This paper highlights a limitation of TCE that we noted above; namely the preoccupation of the theory with the economic conditions that motivate a firm to structure relationships in a particular way without considering other mechanisms and processes that influence these relationships. Joshi and Stump (1999) similarly combine transaction cost analysis and relational exchange theory to understand how various transaction and environmental factors affect the decision to employ joint action agreements, or nonequity arrangements in which manufacturers and suppliers agree to cooperate on certain activities that are of value to both parties, in manufacturer-supplier relationships. Consistent with TCE, their analysis of survey data from firms in three different SIC codes finds that manufacturer asset specificity increases the need for the contractual safeguards found in joint action agreements, but also support research on dependence balancing cited above, noting that when both manufacturers and suppliers commit specific assets the need for additional safeguards is attenuated. These authors further find that the level of decision-making uncertainty and manufacturer trust in the focal supplier—reflected in manufacturers' perceptions of the motives and intentions of their suppliers using a survey 
instrument-influence the effect of manufacturer asset specificity on the use of joint action agreements. Their results suggest that the main effect of asset specificity is strengthened under conditions of high uncertainty. Likewise, whereas TCE would normally predict that high asset specificity transactions would be organized hierarchically, high levels of trust in the manufacturer-supplier relationship increase the use of joint action agreements. These latter two findings on the moderating effects of trust and uncertainty on asset specificity are quite interesting. Data limitations significantly limit the authors’ ability to draw any definitive conclusions about the influence of these factors, however. ${ }^{27}$ Additional efforts to outline the use of relational contracting and hybrid governance modes to manage marketing relationships include Kim's (1999) analysis of joint action agreements, Stump and Heide's (1996) work on the interdependence of contractual provisions to control opportunism, Anderson and Weitz's (1992) research on pledges and Bucklin and Sengupta's (1993) analysis of marketing alliances. Brown et al. (2000) similarly find that norms of relational exchange, along with relationship specific investment and ownership and various combinations of these governance mechanisms, are effective at managing marketing channel opportunism. Governance modes can usefully be described as comprising specific clusters of features - where the particulars of the features vary especially within hybrid forms. The presence of alternative normative structures may enhance firms' abilities to structure relationships and therefore need to be considered in the contracting decision calculus.

Two other empirical phenomena that illustrate the applicability of TCE to marketing are sales force control and industrial purchasing strategies. In their analysis of industrial product manufacturers, John and Weitz (1989) find that the percentage of salesperson compensation that is paid in salary is positively related to behavioral and environmental uncertainty. Anderson's (1988) study of the electronics component industry finds that increasing asset specificitymeasured as the extent of salespersons' specialized knowledge and relationships acquired through experience-increases the frequency of opportunistic behavior. Noordewier, et al.'s (1990) 
analyze industrial purchasing strategies, with survey results suggesting that organizations that introduce more relational factors into their purchasing agreements experience lower acquisition costs in the face of uncertainty. Finally, Stump and Heide (1996) explore supplier opportunism in chemical manufacturers' industrial relationships, and find different control mechanisms, including partner selection and supplier-specific investments, vary with the attributes of the transaction.

\subsubsection{Accounting}

Compared to the extensive work in economics and marketing outlined above, there are

fewer direct applications of TCE reasoning to empirical problems in accounting. ${ }^{28}$ This relative dearth of TCE research is somewhat surprising given the apparent relevance of accounting phenomena to questions of economic organization and performance. Coase (1990), in particular, suggests that accounting issues are important in explaining why the cost of organizing particular activities differs across firms, and notes that when accounting measures are difficult to specify precisely because of the nature of firms' activities, the costs of organizing are likely to be greater as either more mistakes will be made or additional costs will be incurred to avoid these mistakes. As a result, the activities with which firms undertake are, at least in part, influenced by their effect on the efficiency with which the accounting system operates. ${ }^{29}$ If the hypothesis put forth by Coase (1990) is correct, TCE factors are clearly relevant to a range of issues with which accounting scholars are concerned.

The direct application of TCE in accounting is relatively scarce, but it has appeared in some important recent work. For example, Cooper \& Slagmulder (2004) examine the effects of strategic alliances on cost containment. Characterizing strategic alliances as hybrid relational contracts, the authors observe that these intermediate organizational structures enable contracting parties to collaborate to enact interorganizational cost management. Harris \& Livingstone (2002) observe that tax rules can also affect a firm's transaction costs. In observing the effect of new tax legislation that imposed caps on certain CEO compensation, the authors argue that the law 
reduced the implicit contracting costs to negotiate compensation, which ironically (and contrary to legislative intent) led to an increase in CEO compensation for many firms. Together, these studies reveal the interaction between organizational form and the accounting of costs. While Harris \& Livingstone (2002) establishes that exogenous accounting rule changes affect a firm's governance costs, Cooper \& Slagmulder (2004) illustrates that innovative organizational forms bear upon a firms ability to employ accounting strategies to reduce production costs.

Efforts to examine the relationship between accounting policies and contracting behavior have recently appeared in the accounting literature, although only a few of these studies explicitly take a TCE approach. For example, research on debt covenants highlights how contracting parties incorporate and treat potential changes in accounting regulations. The debt covenant hypothesis maintains that firms select accounting methods so as to introduce slack into debt covenant constraints. Lacking this slack, firms may find themselves in violation of their debt covenants if regulatory changes require the use of new accounting methods. Mohrman (1992; 1996) suggests that firms may in fact anticipate the possibility of such regulatory changes, however, and protect themselves by more completely specifying the accounting methods that will be used to determine covenant compliance, regardless of subsequent changes to generally accepted accounting principles. Mohrman's discussion of debt covenants is extended in Warfield et al.'s (1995) examination of managerial ownership and the choice of accounting procedures. Drawing on work by Williamson (1964) and Jensen and Meckling (1976), among others, these authors explore how the separation of corporate ownership and control affects both the informativeness of accounting earnings and the accounting choices of managers. The authors hypothesize that contracts are written to constrain managers from pursuing non-value maximizing actions, among other things, when ownership and control are distinct. Since these contracts contain accounting-based constraints on managers' actions (e.g., debt covenants and corporate charters), corporate management adjusts reported accounting numbers to relieve these constraints. The authors’ analysis of 1,600 corporate accounting reports finds that management discretion with respect to 
accounting choices is inversely related to managerial ownership and the informativeness of accounting earnings in explaining stock returns increases with managerial ownership. Beatty et al. (2002) find a similar premium for accounting flexibility in discovering that borrowers are willing to pay as much as an additional 84 basis points on a loan to exclude accounting changes from covenant compliance determinations.

Although much of the work cited above does not directly test TCE predictions, it does speak to important aspects of TCE theory. Warfield et al.'s (1995) work recognizes the use of employment contracts to mitigate managers’ opportunistic behavior, and Beatty et al. (2002) recognizes the same for debt contracts. The results from both studies suggest that accountingbased contractual constraints encourage managers to exploit the latitude available in accepted accounting procedures to alleviate constraints or engage in other non-value maximizing behavior. The suggestion that greater managerial ownership is a mechanism to control these opportunistic tendencies is entirely consistent with Williamson's $(1964 ; 1985)$ discussion of the organization of labor. Mohrman’s work is similarly consistent with farsighted contracting laid out by Williamson (1996). The usefulness of transaction cost economics to accounting, as well as other business- and non-business-related fields, depends on a determination of where the comparative institutional action resides. If it is the case that accounting policies are manipulated more so under markets than hierarchy, for example, then the benefits of applying TCE are readily evident. If there is no difference in manipulation from these distinct organizational forms, then TCE is less useful.

\subsubsection{Finance}

Relative to accounting, the use of TCE reasoning in finance is more established, with at least two active research streams. The first explores the role of governance structures in diversifying or reducing financial risk. Woodward (1988), for example, explains the use of deposit insurance in transaction cost economizing terms by arguing that banks are essentially institutions that collect and assess financial information and write loan contracts. Because these loan contracts entail various levels of risk, banks attempt to diversify their loan portfolios by 
selling or trading loans with other banks. ${ }^{30}$ While many loans are “marketable,” loans involving highly idiosyncratic investments or for which information is "impacted" may in fact be untradable. Given the non-fungibility of such bank-specific assets, Woodward (1988) argues that alternative mechanisms for reducing financial risk, such as government-sponsored deposit insurance, may be more socially efficient.

While Woodward (1988) employs TCE reasoning to fuel policy reform, most finance scholarship explores how private institutions employ alternative governance structures to reduce the cost of financial risk. Helfat and Teece (1987), for example, examine the relationship between vertical integration and uncertainty and hypothesize that the information sharing and incentive alignment properties of hierarchy reduce firms' exposure to uncertainty. ${ }^{31}$ If vertical integration can reduce firms' uncertainty exposure and the risk that investors face in holding the firm's securities, then its cost of capital should be lower than otherwise. The authors examine U.S. firms involved in vertical mergers between 1948 and 1979 and find that vertical integration is associated with a reduction in systematic risk, suggesting that integrated firms have cost advantages in raising equity capital. Spiller (1985) finds similar results in a comparison of market power and TCE explanations of the risk reduction associated with vertical mergers. In particular, vertical mergers between firms with geographically proximate, vertically-related facilities (one measure of site specificity) shows the largest stock gains from merger, as well as a larger risk reduction in systematic risk, when compared to the effect of the industry concentration ratio. These results support the asset specificity explanation for mergers over the market power explanation, highlight the risk reduction characteristics of integration, and bring doubt to whether vertical integration creates financial barriers to entry. Villalonga and McGahan (2001) employ stock valuation, rather than the cost of debt, as an indicator of optimal risk allocation and test whether financial markets react differently to transactions—proxied for by acquisitions and alliances - by alternative forms of governance. Using an event study analysis of stock market reactions to more than 9,000 deals announced by Fortune 100 members between 1990 and 2000, 
the authors find no single governance form is optimal for all deal types and conclude that firms self-select governance structures optimally to reflect the idiosyncratic contingencies of each deal.

The second TCE-related research stream in the finance literature relates to the choice of debt versus equity financing. Williamson $(1985 ; 1988)$ argues that debt and equity are alternative forms of governance and that the optimal financing approach depends on the characteristics of the assets—-particularly the redeployability of these assets—in a given instance. Debt, which represents a market mode of organization, is favored when asset specificity is low whereas equity, the equivalent of internal organization, is favored when relationship-specific investments are more prominent. Balakrishnan and Fox (1993) explicitly test this proposition in their examination of financing data of single business firms across 30 industries and find strong support for the hypothesis that firms' use of debt is positively related to the redeployability of existing assets and for the hypothesis that firms that invest heavily in R\&D (which potentially creates intangible and firm-specific know-how) are less likely to finance such investments with debt. Inderst \& Muller (2003) employs similar logic to examine when firms use "centralized” contracts to finance multiple projects through a headquarters and when firms use “decentralized” contracts in which projects separately raise funds in the external capital market.

Other more focused applications of TCE to finance include Perry and Robertson's (1998) research on the effects of uncertainty on bond markets, Bergh and Lawless' (1998) analysis of portfolio restructuring, Bjuggren's (1995) research on capital structure, Erridge, et al.'s (1999) discussion of competitive tendering, and Baranoff and Sager's (2003, 2004) examinations of life insurers. Transaction cost logic has broad applicability to empirically researchable issues of concern to finance scholars, and the work mentioned here suggests strong and growing support for transaction cost predictions.

\subsubsection{Organization Theory}

An area in which transaction cost economics makes an important contribution and has had considerable empirical influence is organization theory. Although its economic origins 
distinguish it from other organization theory perspectives, most notably sociology, psychology, and political science, TCE's serious analysis and comparative approach has seen broad interest among organization theorists. Chief among TCE's contribution to research in organization theory has been to heighten awareness of efficiency considerations (Carroll, Spiller et al. 1999). This awareness has prompted organization theory scholars to reexamine many long-standing research problems in a new light, which has led to a substantial collection of published empirical work. We identify more than 30 articles that explicitly bring together and test insights from organization theory and transaction cost economics, while many other empirical papers that are not included in our review have important implications for, or are in the spirit of, TCE theory. ${ }^{32}$ These TCEoriented approaches examine a broad range of issues and relate to a number of different perspectives in the organization theory literature.

Among the perspectives in which TCE has had a notable impact on empirical work is institutional theory. ${ }^{33}$ Institutional theorists claim that organizational structures arise and are adopted because there is normative consensus about which modes of organization are most appropriate for a given activity. While institutional theory typically eschews efficiency motivations and in this respect is clearly at odds with TCE, a number of scholars have explored the intersection between TCE thinking and institutional theory's emphasis on trust and social norms of exchange. Many of the more recent studies explore the relative explanatory powers of the two approaches. Hughes et al. (1997), for example, examines organizational change in the Welsh National Health Services (NHS) from both a transaction cost and institutional theory perspective. The authors find that the NHS's contracting practices are highly influenced by regulatory policy intervention. Periods of relative stability and incremental development of contracting practices are punctuated by major shifts in policies that impose changes in contracting behavior and monitoring practices. They conclude that in such an environment organizational change is better understood as resulting from mimetic and coercive isomorphism than from efficiency calculations. Zaheer and Venkatraman (1995) similarly emphasize the role of 
normative pressures and trust in exchange relationships. Combining traditional TCE reasoning with institutional theory's notion of trust, the authors develop and test a model of relational governance on survey data collected from 329 independent insurance agencies. Consistent with TCE predictions, the authors find that the presence of asset specificity is positively associated with more hierarchical modes of governance, and that the inclusion of various proxies for the level of trust that exists in these contractual relationships yields a statistically significant increase in the predictive power of the model. Lee, et al. (2003) applies this theoretical template to examine succession in family-controlled businesses and, in contrast to the conventional presumption of nepotism, proposes a transaction-cost economic rationale to argue that family succession is a solution to common agency hazards and the appropriation risk in human capital investments. Richman (2006) offers a similar explanation in a microanalytic examination of family-run diamond firms.

Many studies have used both TCE and organizational theory to understand strategic alliances between firms. Most of this work models interorganizational trust and relational exchange as governance mechanisms, in which trust can replace hierarchical devices. Gulati and Singh (1998), for example, find that trust plays an important role in alliance formation and suggest that firms with repeated ties—-their proxy for interorganizational trust—are less likely than first-time alliances to be organized as joint ventures or minority equity investments than as contractual alliances. The interplay of transactional features and social norms is also emphasized in Arrighetti et al. (1997) and Zaheer et al. (1998) and work in relational exchange theory, including Pilling et al (1994) and Heide and John (1990; 1992). Dyer and Chu (2003) obtained similar results in an international sample of supplier-automaker exchange relationships. And some studies use organizational theory to bring greater clarity to the transactional challenges that confront strategic partners. Artz and Brush (2000) found that relational norms directly reduced exchange costs by altering the behavioral orientation of strategic alliances, and Casciaro (2003) observed that uncertainty surrounding the market environment and commercial objectives, not 
just the level of trust between cooperating firms, determines the governance structure of strategic alliances.

Organizational ecology represents a second organization theory perspective in which TCE logic is frequently employed. Organizational ecologists view organizational structures as highly inertial and resistant to change, and as a result, organizational change is portrayed as occurring through selective replacement rather than individual adaptation. The main empirical emphasis in this perspective is on examining populations of organizations over long periods of time and identifying the environmental factors that affect founding (i.e., organizational legitimacy) and organizational failure rates. Although TCE and organization ecology have a different orientation and disagree about how quickly organizations change, efforts are being made to empirically link these two perspectives. For example, Park and Russo (1996) employ logic from organizational ecology and TCE to explain the failure of joint ventures in the electronics industry. The foundation of their approach is that a joint venture is an intermediate form of governance that exhibits some properties of both markets and hierarchies, and as a result, is subject to analogous hybrid forms of transaction hazards attributable to both ends of the governance continuum. Drawing on earlier work by Freeman et al. (1983), Park and Russo (1996) analyze 204 joint ventures and find strong support that organization failure rates decline according to both transaction and age dependence hypotheses. Osborn and Baughn's (1990) also bring together aspects of TCE and organization ecology in their analysis of inter-firm alliances with similar results. Zylbersztajn and Lazzarini (2005) illustrate that these principles are not limited to measuring the life spans of organizations but can also model the duration of certain contractual relationships.

One interesting and promising approach to integrating organization ecology and transaction cost theory is explored in Silverman et al.'s (1997) analysis of the mortality of large motor carriers in the American for-hire interstate trucking industry following deregulation. The authors find that, consistent with population ecology, density effects of both large and small truck 
carriers generate competitive pressures on large truck carriers and decrease their survival chances. However, carriers that align their capital structure according to TCE reasoning are less likely to fail. Most important, the authors find that while both organization ecology and TCE provided insights into truck carrier mortality, the inclusion of predictors derived from both disciplines significantly increases the explanatory power over either theory evaluated independently. An important advantage of this interdisciplinary research approach is that it not only allows for the testing and comparison of predictions from different research approaches, but also examines the more general mechanisms of organizational change, selection and adaptation.

A number of other attempts to link predictions from transaction cost theory and organization theory has been employed in the literature. These include Freeland's (1996) and Hill's (1988) examinations of the M-form of organization, DeBruin and Dupuis's (1999) analysis of networks, and Eccles and White's (1988) examination of authority. The support for TCE predictions across these various studies is generally positive, but in a number of cases TCE logic is portrayed as either ill-suited to analyze the issues at hand or having limited predictive power when compared with insights derived from other perspectives. Reconciling these contradictory findings awaits further research. ${ }^{34}$ In part, differing empirical results such as these reflect different orientations and methodological approaches. While most organization theorists are sympathetic to efficiency considerations, they nevertheless hold that institutional and political considerations predominate (Hannan and Freeman 1984). It therefore stands to reason that a healthy tension should both exist and persist between TCE and organization theory. Notwithstanding these points of departure, our own review supports Carroll et al.'s (1999) assertion that organization theory is an "interesting and fertile area for cross-discipline exchange and debate [with TCE].”

\subsubsection{International Business}

International business is an area where the influence of transaction cost economic on empirical work is increasingly evident. A major research strand in international business 
examines how firms organize their entry into new international markets. Among the first empirical TCE examinations in this area is Gatignon and Anderson's (1988) analysis of how integrative U.S. multinational firms' international manufacturing operations are and should be. Utilizing 1,267 foreign subsidiaries that were launched between 1960 and 1975 by the 180 largest U.S. multinational corporations (MNC), the authors examine the use of four governance structures that progress from high control to low control: wholly-owned subsidiaries, MNC majority equity, balanced partnerships, and MNC minority equity. In addition to standard transaction level factors, the authors hypothesize that various cultural and political characteristics (e.g., country risk) and firm-level characteristics (e.g., foreign experience, advertising intensity and cultural similarity) also influence the organization of international operations. Employing a multinomial logit model, the authors find that country risk, experience and asset specificity (as measured by R\&D intensity) are important determinants of whether or not firms chose to vertically integrate with the subsidiary. ${ }^{35}$ Although the authors are able to predict the extremes of the governance choice (i.e., high versus low control modes), they are unable to explain lowercontrol entry modes (i.e., majority, balanced or minority stakes for the MNC). The model's relatively poor fit with respect to these intermediate forms is partially explained by omitted variables and measurement problems related to the proxies used for asset specificity and country risk. $^{36}$

Several papers have attempted to develop and extend Gatignon and Anderson's early work. Hu and Chen (1993) employ a similar methodological approach but focus solely on foreign ownership in Chinese joint ventures. They find that socio-cultural and political risk factors have a significant impact on the percent ownership of foreign partners in joint ventures with Chinese companies. Specifically, investors sharing the same ancestral roots as mainland Chinese businesses tend to be more familiar with Chinese business practices, and are thus able to exercise control over their business partnerships by means other than equity. In contrast, the risk embedded in a venture as measured by the duration of the commitment and the amount of foreign 
investment is positively related to greater foreign equity in joint venture arrangements, which implies that foreign firms facing greater risk to their investments will attempt to safeguard these investments with greater equity control over the joint venture. Gomes-Casseres (1989), Cooke (1997), and Murtha (1993) also prominently feature the importance of transactional, political and socio-cultural factors in their analyses, and find overall that TCE provides an insightful context within which to understand foreign market entry decisions.

Research examining how MNCs enter into foreign markets has exhibited significant growth of late, and consequently, Gatignon and Anderson's initial findings have enjoyed some refinement. For example, Doh, et al. (2004) examined newly consummated telecommunications infrastructure projects in various host states and discovered an inverted U-shaped relationship between investment policy hazards and private ownership. The authors explain that private owbnership is most fruitful at intermediate levels of uncertainty, whereas low levels of political hazards induce investors to proceed with governance alternatives to vertical integration and high levels of uncertainty scare away investors altogether. Reuer and Arino (2002) employ transaction cost logic to predict “misalignments” of chosen governance structures for international strategic alliamces, and they gather data on the incidence of contractual renegotiations and the restructuring of alliances for their empirical test. Lastly, Zhao, et al. (2004) surveys a number of different empirical examinations on MNC entry strategies and conducts a meta-analysis on the assorted studies. The meta-analysis confirms the accuracy of transaction cost predictions.

Until recently, the international business literature has been plagued by two critical concerns. First, efforts to capture the net effect of political hazards on multinational strategy have suffered from inadequate definition of an independent variable or variables corresponding to country risk. A number of studies equate countries’ political hazards with managers' perceptions of political risk in those countries. Such subjective measures introduce endogeneity problems, however, as multinational managers choose not to invest in areas they perceive as hazardous, ceteris paribus. Other studies attempt to correlate political hazard to countries' existing political 
institutions and preferences (e.g., democracy versus autocracy or regime stability). Yet, whether an unstable democracy or a stable autocracy is more preferable to foreign investors is not obvious. Instead, it is likely that what matters most to multinational mangers is the extent to which future policies (e.g., taxation and regulation) can be forecast and how sensitive these policies are to changes in the current political environment. Recent work by Henisz $(1998,2002)$, Henisz and Zelner (2001), and Delios and Henisz (2000) begins to rectify these problems by employing a more objective measure of the feasibility of policy change and comparing its effectiveness in predicting market entry modes. This measure is derived from a formal model of political interaction incorporating data on the institutional structure and distribution of preferences both across and within different branches of government for 160 countries. Henisz $(1998,2002)$ employs this political risk calculation along with transaction level factors in analyzing the choice of joint venture versus majority owned plants. He finds that the probability of choosing a majority-owned plant is declining in independent political hazards (consistent with the observation that where political hazards are high, multinationals rely more heavily on hostcountry partners to provide them with safeguards against state-sector opportunism), political hazards magnify the expected impact of contractual hazards (suggesting that majority-owned plants are favored relative to joint ventures due to the concern of opportunistic use of the state by host-country partners), and a weak link exists between transaction level factors (i.e. asset specificity as proxied by R\&D intensity and advertising intensity) and market entry mode.

This last finding reflects a second concern associated with applying TCE in the international business arena. Most of the empirical TCE-related articles in international business employ advertising and R\&D intensity as measures of asset specificity. Unfortunately, the use of such high-level accounting proxies likely confounds multiple influences on governance choice, and the results obtained are difficult to interpret. The lack of support for traditional TCE variables in explaining multinational governance choice could reflect a misspecification of key variables rather than a lack of fit between data and transaction cost theory. Notwithstanding these two 
concerns, TCE logic has yielded important insights into the process by which firms organize multinational transactions. Particularly noteworthy has been the use of TCE in articulating the impact of political factors on contractual hazards and the governance modes employed for multinational ventures.

\subsubsection{Strategy}

Assessing the empirical influence of TCE on business strategy is a difficult exercise due to the nebulous boundaries of the strategy field. Broadly defined, virtually all of the articles discussed in the previous sections could be considered as relating to strategy or strategic business decisions. A more narrow definition of strategy, one confining itself to relating a firm’s resource allocation decisions to its performance, produces a considerably smaller number of articles that speak directly to this area. Nevertheless, the opportunities for TCE to contribute to an understanding of strategic management are considerable (Williamson 1999).

Among the areas in which TCE has begun making important contributions to strategy is in understanding the performance implications of relationship-specific investments and organizational form. Bensaou and Anderson (1999), for example, explore the motivation of firms to make relationship specific investments. Using data from a sample of 388 supply relationships involving all automakers in the U.S. and Japan, the authors examine features of the supply task, the supplier, and the supply environment—all of which bear on the incentives of firms to make supplier-specific investments_-and explore potential factors which facilitate the posting of specific assets as “credible commitments” to attenuate supplier opportunism. Their results suggest that specific assets by buyers serve as a mechanism to increase coordination when the manufacturing task is complex; buffer the buyer against technological uncertainty; and build close relationships when supply markets are thin. Relationship specific investments in industrial suppliers appears to be a mechanism to absorb unpredictability stemming from a fast pace of technological change in the component market as well as a means to cope with component 
complexity. Firms therefore strike a balance between the performance advantages of cospecialization and the hazards of unprotected exchange around these assets. ${ }^{37}$

In an emerging body of research, scholars are moving beyond looking just at the performance effects of relationship specific investments to consider the performance implications of organizational form. For example, Bigelow (2001) and Silverman et al. (1997) both examine the performance effects of transactional misalignment and organizational form, and Allen and Phillips (2003) find that long-term block ownership between collaborating firms increases equity prices, investment, and operating profitability.

In addition to work on performance, TCE is increasingly being linked to other strategic perspectives of the firm. Silverman (1999) examines how contractual hazards affect the likelihood of corporate diversification from joint TCE and resource-based view (RBV) perspectives. According to early work in the resource-based view, firms grow primarily as managers find new uses for resources that are currently going unused (Penrose 1959). Firms are therefore more likely to enter new markets as resources become available, but less likely to divest. In contrast, TCE suggests that there are multiple ways in which excess assets may be utilized, including contracting these assets to outside parties and/or spinning them off into standalone enterprises (Teece 1980). The added incentive intensity associated with exploiting excess resources through markets rather than internally provides a rationale for utilizing various contracting approaches. Silverman (1999) argues that the relevant empirical question with respect to diversification is therefore, under what circumstances are excess resources more suitably exploited through internal diversification than through outside contracting. Drawing on work by Teece (1986), Silverman finds that the contractual exploitation of technological knowledge resources (e.g., licensing) is a feasible alternative to diversification except for cases where the knowledge is highly tacit or easily transferred but weakly protected. ${ }^{38}$ Bethel and Liebeskind (1998) and Brouthers and Brouthers (2000) apply similar transaction cost reasoning to diversification, and de Figueiredo and Kim (2004) apply it to firms’ political lobbying strategies. 
In a similar interdisciplinary approach as Silverman (1999), Nickerson et al. (2000) link transaction cost economics to Michael Porter's strategic positioning framework (SPF) in an examination of the international courier and small package services industry in Japan. The authors contend that SPF and TCE, if examined in isolation, lead to inferior statistical performance as compared with a joint positioning-economizing lens which better predicts firms’ choices around market position, resource profile and organization. Hoetker (2005) extends this multi-theoretical template even further by incorporating TCE, relational contracts theory, and the capabilities literature in a single integrated model that predicts supplier relationships for innovative components. Other efforts to utilize TCE to explore issues relating to strategy include Nickerson and Vanden Bergh (2001), Argyres (1996), and Kim (1999).

\subsubsection{Summary}

The evidence explored in the previous seven subsections of this paper on the applicability of transaction cost analysis to empirical problems across several business-related phenomena is impressive. With the exception of accounting, there has been a significant growth in the use of TCE reasoning across the various business-related fields that we examine. The articles reviewed suggest overall that transaction level factors have an important influence not only on contracting and governance choice, but also on organizational performance and survival. While a number of theoretical concerns and oversights are also identified (some of which are discussed in greater detail below) there is considerable empirical support for the basic transaction cost framework. Decisions regarding how best to organize transactions in a host of different business fields appear to be shaped by concerns over the comparative costs of planning, adopting, and monitoring task completion under alternative governance structures. Most important, the application of TCE reasoning in areas outside of mainstream IO has led to important extensions of the theory. As the discussion of the accounting and strategy literatures suggests, however, there are clearly areas in 
which transaction cost logic has not been applied—possibly because of underutilization or because it has less application.

\subsection{NON-BUSINESS AREAS}

The previous section examined the use of TCE theory in several business-related fields, but transaction cost analysis has important theoretical and empirical implications for a host of other areas as well. In particular, TCE has been influential in the areas of law, public policy, as well as health economics and policy and agricultural economics and policy. It is to these areas that our analysis now turns.

\subsubsection{Law and Public Policy}

While the earliest applications of TCE theory examined public policy issues such as antitrust and regulation, ${ }^{39}$ TCE reasoning is increasingly used to examine a wider variety of legal and public policy-related issues. Three areas are particularly evident in the collection of the 150 articles we identify as being mainly law- or policy-oriented for this survey: regulation, political institutions, and development and reform.

Much of the earliest empirical TCE work in law and policy centered on providing a response to natural monopoly rationales for regulation, particularly with respect to public utilities. This literature, which has been reviewed elsewhere (Crocker and Masten 1996), provides early critiques of the natural monopoly approach to utility regulation noting that, while technological conditions may require one supplier, whether that supplier should be regulated by the state or market-like mechanisms is a separate question. Williamson (1976) sets out the comparative TCE logic of this choice and explores the implications with a case study of alternative governance mechanisms to allocating cable TV services rights in general and with reference to the experience in Oakland, California. Williamson suggests that the choice between market control and regulation hinges fundamentally on the presence of contractual hazards. Complex or uncertain environments in which contractual parties are asked to make relationship-specific investments require more hierarchical mechanisms of control; in this case, mechanisms that look very much 
like government regulation. Subsequent work by Prager (1989; 1990) and Zupan (1989) provide extensions of these basic insights. Transaction cost analysis has also been employed in examining private contracting under alternative regulatory regimes (Palay 1984; 1985; Baker and Chapman 1989; Alger and Toman 1990; Phillips 1991; Jensen and Rothwell 1998).

Joskow (1996) more recently employs a comparative governance approach in his analysis of efforts to introduce competition into regulated electricity markets. According to Joskow, the evolution of the governance structures of the electric power sectors around the world (which rely extensively on multilateral agreements and vertical and horizontal integration) can be explained as potentially efficient organizational arrangements for dealing with vertical coordination and network externality problems that are intrinsic to modern electricity networks. As a result, the electricity sector evolved with regulated or government-owned monopolies and limited opportunities for competition. Because these monopolies create their own costs, however, a tradeoff is posed between the costs associated with regulated monopolies and the benefits of operational and investment coordination within integrated industrial hierarchies. In recent years, countries have concluded that the costs of monopoly governance modes in this sector outweigh the benefits, and are therefore implementing structural reforms to promote competition in the supply of generation services and are creating new governance structures to maintain efficient short-term coordination relationships between generators and the network, to manage network constraints, and to internalize network externalities. Joskow suggests that this process poses serious institutional design problems, and counsels that reforms (including deregulation) should focus on finding new governance structures that are good substitutes for the pre-reform vertical and horizontal hierarchical and contractual structures that are being broken down to promote competition at certain horizontal levels. Drawing on TCE reasoning, Joskow outlines the various nuances of this design problem and highlights the long-term performance implications for the electricity sector. 
One important contribution coming out of the comparative institutional approach is to highlight the efficiency rationales for governance arrangements that have historically been viewed as anticompetitive by academics, regulators, and courts. A recent illustration of this sort of analysis is Heide et al.'s (1998) work on exclusive dealing clauses. A central issue in the public debate over exclusive dealing arrangements has been the relationship between these arrangements and efficiency. Using survey data collected from manufacturers in the industrial machinery/equipment and electronics industries, the authors find that business efficiency factors play a significant role in firms’ decisions regarding exclusive dealings. In particular, firms are more likely to use exclusive dealing when there is a potential that other firms can free ride on the services they provide. The authors also find that difficulties with evaluating distributors’ adherence to assigned restrictions decrease the likelihood of using exclusive dealings in the first place. These results indicate that TCE considerations play an important role in highlighting the utility, and thus endorsing the legality, of vertical restraints. A more sweeping conclusion is reached in Joskow (2002), which after examining the TCE implications for antitrust law pronounces that “[m]odern imperfect competition theory that fails to take TCE principles into account is likely to lead to poor legal rules and remedies.”

In addition to the empirical work that examines regulation, TCE theory is used to examine the various political and legal institutions that safeguard transactions against statesponsored opportunism. This empirical research approach more generally explores the rationale for and efficiency implications of various modes of organizing government agencies and legislatures. Levy and Spiller (1994) suggest that a prerequisite for private investment is the ability of regulators to credibly commit to not pursue arbitrary administrative actions. Comparing the experiences of several countries with respect to the governance of telecommunications transactions, the authors identify three institutional factors that contribute to a society's ability to constrain government discretion. ${ }^{40}$ In countries where these institutional factors are lacking, licensing arrangements appear to be the best mechanism to induce investment. Countries with 
severe institutional weaknesses rely on nationalization to procure the required investments. Alternatively, in countries where these criteria are met, other more balanced approaches that combine flexibility and commitment, such as commission regulation, are utilized. A more detailed analysis of these conditions and, more generally, how countries build and communicate credible commitments is found in Spiller and Vogelsang's (1994) examination of the British telecommunications sector. A number of subsequent studies provide additional empirical validation to the importance of political institutions to firm investment decisions. Among these are Henisz and Zelner's (2001) and Bergara et al.'s (1998) analyses of international utility sector infrastructure investments. Other papers that explore the importance of credibility in supporting nonredeployable investments include Grandy (1989), Montignola et. al (1993), Troesken (1997) and Che and Qian (1998). Among the important conclusions that emerge from this literature are, first, that the regulatory regime and the political environment jointly contribute to the level of credibility that exist in a given setting, and second, different governance mechanisms can create regime stability and credibility.

Much of the research cited above has been instrumental in the application of transaction cost economics to a third area of law and policy: development and reform. The political changes taking place in Eastern Europe and parts of Asia created significant opportunities for scholars to explore transaction cost analysis in understanding market transitions. Janet Landa’s (1981, 1988, 1994; Carr \& Landa 1983) extensive work on ethnic networks, including her "ethnically homogeneous middleman group” theory, uses transaction cost logic to explain the success of certain groups in countries without developed legal institutions or reliable contract enforcement. McMillan and Woodruff (1999) examine contracting and dispute resolution mechanisms that make use of community sanctions and other specialized governance structures to compensate for the inadequacy of the courts in the economic reform currently underway in Vietnam. And Delios and Henisz (2000) examine how organizational capabilities and public and private expropriation hazards influence the level of equity investments in foreign subsidiaries in emerging markets. 
Their results suggest that a firm’s prior experience enhances hazard-mitigating capabilities and thus reduces sensitivity to public and private expropriation hazards, leading to increases in equity ownership in foreign subsidiaries. Governance arrangements that mitigate contractual hazards in emerging economies are similarly examined in Choi, et al. (1999).

The focus on governance modes and commitment that permeates the previously mentioned empirical studies is also found in Shirley and Xu's (1998) examination of incentive contracts between developing country governments and the managers of state owned enterprises (SOEs). One of the key problems in developing countries is improving the performance of SOEs, and incentive contracts that are similar to the contracts between management and owners of private firms have been suggested as a potentially effective tool. Drawing on TCE reasoning, the authors suggest that contractual problems stemming from information asymmetry, incentive misalignment and a lack of state commitment undermine the use of incentive contracts in this setting. Their analysis of contracts from the largest SOEs in 32 developing countries finds no evidence that incentive contracts improved SOE performance because the governments in their sample chose to pledge actions that they were not motivated or able to implement.

The influence of governance on transaction costs is likewise seen in Nee’s (1992) analysis of the emergence of various hybrid forms of organization as part of reform efforts in China. To explain the evolution of these hybrid modes, Nee argues that the Chinese political environment and the nature of market reforms give these organizational forms an economizing advantage over alternative governance arrangements. In particular, these arrangements are comparatively more adept at managing the institutional uncertainty and weak property rights that exist in China relative to either hierarchical state-owned enterprises or smaller family-owned peasant farms. He also notes that these forms may be transitional. In particular, as the Chinese economy continues to move from state socialism to a market orientation, these hybrid forms will increasingly give way to private forms of organization. Additional applications of transaction cost economics to development issues are found in Menard and Shirley (2000), Che and Qian (1998), 
Husted (1994) and Bertero (1997). ${ }^{41}$ The policy implications of this work are difficult to understate as developing countries consider implementing a host of new and unproven approaches. The papers mentioned above, as well as related works, provide much needed empirical and theoretical perspective on many of these reforms.

Importantly, the study of political institutions using a TCE framework has not been limited to examining the ability of systems to create and communicate credible commitments. To the contrary, important expansions of transaction cost analysis have extended into understanding the operation of public institutions themselves. For example, TCE-motivated contract theory has examined how government agencies subcontract with private firms (Ciccotello et al. 2004), whether agencies externalize certain functions (Nelson 1997; Kavanagh and Parker 1999), and how agencies construct governance structures to monitor firms (Delmas and Marcus 2004). In addition, TCE has proved fruitful in applying institutional analysis to political institutions just as it does to firms and private institutions. Notable examples include examinations into the internal organization of legislatures (Weingast and Marshall 1988) and bureaucracies (Moe 1990), the institutional arrangements between different branches of governments (Weingast 1995; Saalfeld 2000), the mobilization of political parties (Wielhouwer 1994; Jones and Hudson 1998), the engagement in political lobbying (Alt, Carlsen et al. 1999), the political facilitation of private agreements (Richman \& Boerner 2006), and the making of public policy (Dixit 1996; Spiller and Tommasi 2003). These applications into political institutions might be one of the more important recent developments in TCE research.

\subsubsection{Health Economics and Policy}

A social science area that is increasingly using transaction cost economic logic is public health. One of the main impetuses for this recent interest appears to be the dramatic organizational changes affecting the health care industry. These changes, many of which are driven by regulatory measures and advances in medical technology, have led to reorganization in almost every phase of the healthcare industry, most notably the delivery of medical services to 
patients and payment mechanisms by governments and private insurers. Robinson and Casalino (1996), for example, explore the growing linkages between primary care-centered medical groups and specialists and between physicians and hospitals under managed care in California. The authors evaluate two alternative forms of organization: vertical integration based on ownership; and "virtual" integration based on a network of contracts. The choice of which organization mode is preferable is determined by excess capacity and the need for investment capital in the shortterm, and economies of scale, risk-bearing ability, transaction costs and the capacity for innovation in the long term.

Coles and Hesterly (1998) examine patterns of vertical integration in public and private hospitals and evaluate the impact on institutional form of uncertainty and its interaction with relationship-specific investments. In addition to examining organizational realignment in the healthcare industry, the paper makes two more general empirical contributions. First, it explores how uncertainty moderates or accentuates the effect of asset specificity on the vertical integration decision. Prior empirical studies in TCE have found mixed effects for the role of uncertainty in the make or buy decision, so exploring interaction effects may provide additional insights into the role of uncertainty in key organizational decisions. Second, the paper explores the vertical integration decision in a context consisting of both public and private firms. It has been suggested that public entities are much less sensitive to efficiency pressures than are private firms, so analyzing key organizational decisions in a setting in which both types of firms compete should elucidate these differences. Coles and Hesterly (1998) examine individually the integration of specific services and find that increased uncertainty induces firms to integrate at lower levels of asset specificity, ${ }^{42}$ and that the effect of asset specificity is less pronounced and consistent than the effect of uncertainty when interacted with asset specificity. Interestingly, the authors find that these results are driven primarily by the private hospitals in their sample while integration decisions in public hospitals do not appear to be influenced by TCE variables. This likely reveals that public institutions have different incentives than private hospitals even though they operate in 
the same competitive space, and that other incentives (e.g. political factors) have a greater impact than do transaction costs.

In a similar study, Ashton (1998) examines four types of contract health services—rest homes, primary care clinics, surgical services and acute mental health services—in New Zealand. Using interviews with purchasers and providers, the costs of contracting for these health services correlate with measures of asset specificity, uncertainty, frequency and measurement. Contracting for acute mental health services is found to be most costly, and this form of organization was also found to score "high” on asset specificity, "medium/high” on uncertainty, "recurrent” on frequency and "high” on measurability problems. Rest homes score low on asset specificity, uncertainty and measurability and “occasional” on frequency, and appear to have the lowest cost of contracting. The other two types of contract health services fell in between with respect to both the attributes listed above and the cost of contracting. A similar study by Zinn, et al. (2003) evaluated examined decisions by skilled nursing facilities to provide rehabilitation therapy by contracted services, by employed staff, or by a mix of the two. Consistent with TCE theory, the authors found that greater vertical integration was associated with increased uncertainty and complexity. Additionally, similar to the findings in Coles and Hesterly (1998), for-profit providers exhibited greater vertical integration. Perhaps the authors’ most significant finding, however, follows from their longitudinal examination of how nursing facilities responded to the institution of Medicare's Prospective Payment System, which led to greater use of employment over subcontracting. The authors suspect that the PPS's financial incentives increased the transaction costs of contractual relationships.

Zinn, et al. (2003) also offers a window in to differences between health facilities that operate independently versus those associated with a network or chain. Zinn, et al. (2003) found that chain affiliation was associated with greater vertical integration. This finding relates to a multi-theoretical study of hospitals and health systems by Bazzoli, et al. (2000). The authors found that hospitals in health systems that operated under unified ownership generally had better 
financial performance than hospitals in contractually based health networks, and hospitals in highly-concentrated health networks tended to outperform those belonging to decentralized networks. Although the authors concede that their findings are consistent with multiple theories, they suggest the TCE offers insights into how vertical integration might control costs and monitor quality in multi-facility health systems.

Other empirical TCE applications to the public health area include Lehrman and Shore's (1998) analysis of the integration of hospitals and skilled nursing services, Pelletier-Fleury, et al.'s (1997) work on telemedicine, Hodgkin et al.'s (1997) analysis of HMO contracting, Dansky, et al.'s (1996) work on hospital referrals to home health agencies, and Bariletti and France's (1996) examination of competitive strategies in health care.

\subsubsection{Agricultural Economics and Policy}

There has been little systematic statistical analysis of agriculture or the organization of agriculture transactions from a transaction cost perspective. Masten (2000) notes, however, that agricultural transactions display a broad range of governance structures, including the locationspecific nature of the investments required and the temporal specificities associated with the

perishability of agricultural products. ${ }^{43}$ Empirical applications of TCE to agricultural transactions examine issues related to both agricultural economics (more so) and policy (less so).

Masten (2000) indicates that the nature of agricultural products and production means physical and human asset specificities likely play a less important role in agricultural transactions in comparison to the temporal and locational specificities associated with production, processing and distribution of foodstuffs. Food perishability tends to exacerbate contracting hazards between contracting parties, while geographic and process disparities between contracting parties tend to impede the administration and coordination of activities. A number of case studies bear out the connection between hold-up problems and temporal and locational specificities, including Knoeber’s (1983) examination of the governance of fruits and vegetable processing and dairy processing, Read's (1983) description of the evolution of organizational arrangements in the 
U.S.-Caribbean banana trade, Gallick’s (1996) analysis of the relations between tuna harvesters and processors, and Larue, et al.’s (2004) study of Quebec’s hog and pork producers and their single downstream processor. Hobbs (2001) similarly uses transaction cost economics to understand how institutions arise in the agri-food industry to send credible quality signals to consumers.

A number of other empirical studies examine the extent and use of long-term contracting in agriculture. Allen and Lueck (1992a; 1992b) study the use of relatively simple short-term contracts in farming and argue that the simplicity of these agreements reflects the comparative advantage of enforcing farmland contracts through the market and common law. The authors suggest that the character of the farming economy - good information about reputations, the immobility of farmers and landowners, relatively low transaction costs and the desire to maintain long-term relationships - lends itself to the pervasive use of informal, simple contracting. Purcell (1990) and Purcell and Hudson (2004) examine the growth of long-term contracting, the rise of vertical alliances, and the prevalence of integration between feedlots and beef processors brought on by the site specificity that exists. Other agriculture-related contracting issues include Lajili et al. (1997), Alston and Higgs (1982), Datta et al. (1986), Allen and Lueck (1993; 1996), and Vernimmen, et al. (2000).

Another empirical research tradition within agriculture that makes use of TCE reasoning is agriculture policy. This work is broad and diverse and includes examinations of such phenomena as downstream food markets (Frank and Henderson 1992), forestry (Globerman and Schwindt 1986; Goedecke and Ortmann 1993) and environmental taxes (Vatn 1998). The most ambitious effort in this area is the Van Huylenbroeck, et al. (eds.) (2004) anthology of twentyeight papers, emerging out of a recent seminar of the European Association of Agricultural Economists, designed to bring conceptual and empirical applications of New Institutional Economics to address Europe’s agri-food industry. 
As Masten (2000) notes, “agricultural transactions provide a rich and largely unexplored area for application and refinement of transaction-cost theory” [p. 190]. That might soon change, for as Allen \& Lueck (2000) state, “[a]gricultural economists, with their knowledge of farming, are well positioned to take advantage of the fertile ground of economic organization.” [p.643]. As is true of the health economics and policy area discussed above, empirical research within agriculture will not only benefit from a transaction cost economic approach, but also help to broaden and advance the theory itself.

\subsubsection{Summary}

The purpose of the previous section is to provide an overview of how TCE has been applied in areas outside of business and especially IO economics. TCE theory has provided scholars with a useful framework to examine phenomena in a variety of different areas, and the results of these efforts have had important strategic and policy implications. In the law and policy discipline, for example, the application of TCE to various forms of regulation has demonstrated that many non-standard forms of contract and organization—once thought to be noncompetitive-may in fact have efficiency explanations. Similarly, the use of transaction cost reasoning to address development and reform issues has provided insights that are of paramount importance to policymakers in developing and former socialist countries. As with the empirical research examined in Section 4.1, however, many of the phenomena examined in Section 4.2 illustrate limits or oversights of transaction cost economic theory. It is to an examination of these issues that we now turn.

\section{ASSESSMENT OF EMPIRICAL TCE RESEARCH}

\subsection{Significant Progress Has Been Made}

Taken together, the papers surveyed provide considerable support for the main propositions derived from transaction cost economic theory. The central hypothesis that governance choice is largely determined by the cost of transacting and that these costs are 
influenced by observable characteristics of the underlying transactions receives overwhelming support in our assessment. There is also considerable support for many of the specific transactionlevel factors identified in the theory as influencing contracting costs. Specifically, the centrality and importance of relationship specific investments, in their multiple forms, is highlighted in many of the empirical articles cited above. The critical dimensions along which governance structures differ are also elucidated in the empirical literature surveyed. The importance of incentives and coordination mechanisms in various governance modes are examined in a host of empirical pieces. How these characteristics differ across different forms of organization is central to this literature, and again, the variation is largely as predicted in the theory. Our survey of the articles finds a remarkable convergence between the theoretical predictions of TCE and the results of empirical applications within several fields of many social science arenas.

Two particularly important conclusions warrant greater discussion however. First, our survey highlights the tremendous range of empirical phenomena that have been explored through the lens of transaction cost economics. Beyond its initial focus on the make-versus-buy decision, TCE has provided a framework for examining the organization of labor, dominant firms, contracting for natural monopoly, non-standard contracting (including franchising, exchange relations and take-or pay agreements), corporate governance, pubic bureaus, and reputation. More recently, researchers have utilized TCE theory in exploring the organization of firm innovation, economic and political reform, privatization, and the performance effects of organizational choice. The theory also provides a useful framework for understanding the ramifications of the empirical phenomena listed above for public policy. The impressive breadth of issues that have successfully been examined using TCE theory is striking compared to other work in Industrial Organization (Joskow 1991; Masten and Saussier 2000). Our findings also appear to validate Williamson's (1985) contention that any problem that can be framed as a contracting problem can be usefully examined through the lens of transaction cost economics. 
A second conclusion of this survey concerns the interest in TCE outside of traditional economic circles. Over the past 15 years, empirical research in TCE has become increasingly multidisciplinary. Although the bulk of empirical TCE articles continue to appear in IO-related economics journals, scholars in other business-related fields and a host of other social science disciplines are successfully and usefully making use of this theoretical approach. TCE is an important theoretical perspective and provides a better understanding of important phenomena in marketing, finance, organization theory, law, policy and a variety of other business-related and non-business-related fields. In many ways, the growing multidisciplinary approach of empirical research reflects TCE's origins as a joinder of economics, law and organization theory.

Interestingly, in addition to being multidisciplinary, TCE is also becoming more interdisciplinary. Scholars are increasingly combining the predictions of transaction cost theory with those of other theoretical perspectives to explain various empirical phenomena. The inclusion of alternative perspectives into received transaction cost theory allows researchers to resolve many of the early critiques of the theory. A number of authors combine neoclassical economics with transaction cost economics in their empirical research. MacDonald (1985) incorporates elements of TCE and Stigler's vertical "life-cycle" of the firm theory in an examination of vertical integration. Spiller (1985) compares asset specificity and market-power explanations of vertical mergers under different competitive conditions. Brown and Partridge (1998) use TCE and monopsony power explanations in an examination of the Demise of 19th Century Crude Oil Exchanges. Likewise, a number of recent papers incorporate TCE theory with organizational theory, competitive strategy, or innovation. Included in this growing list of articles are Silverman et al.’s (1997) analysis of mortality rates for large motor carriers in the U.S. trucking industry, Poppo and Zenger’s (1998) comparison of transaction cost, knowledge based, and measurement cost approaches in explaining boundary choice for nine information services companies and Bigelow's (2001) integration of transaction cost economics and organizational ecology to address questions related to the evolution of firm sourcing arrangements in the U.S. 
automobile industry. Others who integrate TCE with alternative theories of the firm include Argyres (1996), Spiller and Zelner (1997) and Delios and Henisz (2000). These interdisciplinary exercises are useful in the effort to better understand complex economic phenomena and build a coherent science of organization.

\subsection{Lingering Issues}

Despite TCE's growing application, the literature surveyed also highlight a number of theoretical and empirical gaps, which warrant additional discussion. First, considerable work remains to more precisely measure and test for the effects of key transaction cost variables. Measurement issues are particularly evident with respect to the variables used to proxy for asset specificity. These variables are frequently constructed using secondary sources (e.g., accounting data) and, as a result, are often very rough approximations for the underlying concept of interest. For example, some researchers make use of $R \& D$ or advertising intensity as proxies of asset specificity in examining firms' international market entry mode or integration decision, despite its shortcomings and the fact that more microanalytic measures exist (Murtha 1991; Oxley 1997). The problem with such constructs is that they make interpreting empirical results extraordinarily difficult. Assuming these constructs are found to significantly affect a given outcome, it is virtually impossible to discern if the observed effect results from transaction cost considerations or other confounding factors. Although the constraints of secondary data may thwart efforts to develop more exact measures of asset specificity, efforts in this regard are warranted. For instance, researchers may wish to employ multi-measurement approaches to establish the validity of particular constructs prior to testing their main hypotheses. At the very least, a more explicit recognition of the limits of these proxies would be useful. On the other hand, one of the salutary effects of transaction cost economics has been to encourage empirical researchers to collect microanalytic, primary data. This lesson should not be lost as empirical research in TCE continues to progress. 
A second transaction cost construct that has suffered from measurement concerns is opportunism. Although much of the empirical literature employs the general concept of opportunism, and emphasis in TCE has correctly focused on mitigating the hazards of opportunism, the complexity of opportunism has not been fully explored (Wathne and Heide 2000) nor have many studies attempted to measure opportunism directly. TCE expressly adopts the view that economic agents are prone to opportunism, defined as "self-interest seeking with guile" (Williamson 1996). Absent opportunism, transaction cost theory maintains that there is no contractual reason to supplant market with hierarchy (Williamson 1985). Given its theoretical centrality, it is somewhat surprising that the empirical literature is largely devoid of efforts to measure opportunism or examine its prevalence in different contexts. Some sociologists have been particularly critical of this omission, arguing that the concrete relations and social structures that exist in a given institutional setting affect the propensity for opportunistic behavior and, thus, have organizational consequences (Granovetter 1985; Shapiro 1987). While Williamson (1996) appears sympathetic to these arguments, few scholars to-date have attempted to explore empirically how institutional features affect the degree of opportunism that exists in different settings and the organizational ramifications that result. Furthermore, critics of opportunism have generally failed to offer refutable predictions about the implications of a deviance from opportunism (Heide and John 1992). Nevertheless, given the increasing number of cross-national studies employing transaction cost economic arguments, developing the analytical tools to explicitly recognize institutional differences and their effect on the prevalence of opportunism is likely to assume heightened importance.

An issue closely related to the measurement of transaction cost variables is how these variables are utilized in empirical tests. In particular, we found surprisingly few studies that explore the interaction effects among transaction cost variables and between these variables and other potentially relevant factors. This omission is most obvious in TCE contracting studies where researchers frequently code a dummy variable according to whether contracts contain a 
particular provision and then analyze the effect of this variable separate from other contractual provisions. As Masten and Saussier (2000) note, however, this approach may simplify the econometrics but it does so at the expense of ignoring potentially important interactions with other aspects of the contract. Contract provisions are most often chosen simultaneously and, as such, can be expected to interact with one another in sometimes subtle and unpredictable ways (Goldberg and Erickson 1987). Indeed, one contract provision can substantially qualify or even negate the meaning of another. Thus, greater effort to explore these interaction effects in empirical work is warranted. In many cases, limitations on the size and quality of data may prohibit the explicit inclusion of interaction effects in econometric analyses. In these instances, researchers should consider complementing their econometric analyses with case studies. Case studies, while lacking in generality, provide the depth necessary to allow researchers to determine what interaction effects are potentially relevant in a given instance and the importance of these effects on organizational outcomes (Masten and Saussier 2000).

In addition to the problems associated with the use and measurement of transaction cost proxies, a second important gap in the existing empirical literature concerns the endogeneity of transaction cost variables, most notably asset specificity. Virtually all of the studies examined in this paper treat the specificity of assets and the level of a firm's investment in those assets as exogenous. However, these are, in fact, choice variables (Riordan and Williamson 1985). Firm managers make decisions regarding whether or not to invest in specialized assets and the scale of those investments. Strictly speaking, these variables should therefore be treated as endogenous. Only a handful of studies, however, have made efforts in this regard (Lyons 1995; Saussier 2000).

A third important oversight in the existing empirical literature centers on the performance implications of organizational choice. Although much of the literature examined above supports the assertion that transaction cost considerations are important drivers of organizational choice, there are only a handful of studies that explicate the costs associated with failing to align transactions and governance forms. Researchers have tended to skirt this issue by assuming that 
organizations adjust to new environmental conditions fairly quickly. However, misalignment between transactions and governance does occur, and is relevant in a variety of contexts. The relatively few studies that explore the performance implications of organizational choice, notably Silverman et al. (1997), Nickerson and Silverman (1999) and Masten et al. (1991), find that the effects of misalignment can be substantial, entailing lower profitability and higher failure rates. Greater effort in the empirical literature to understand the influence of organizational choice on performance is warranted. Specifically, identifying the organizational factors that are relevant for performance in particular contexts, articulating the factors that affect the speed with which organizations change, and empirically testing for the effects of organizational misalignment are issues that need further explication. One important consequence of efforts in this regard will be to increase the intellectual exchange between TCE and the management and strategy literatures, which have as one of their central foci issues of firm performance.

Finally, empirical work in transaction cost economics would benefit greatly from additional efforts to formalize its theoretical foundation. For the most part, TCE continues to lack the rigorous mathematical foundation first noted by Joskow (1988). As Williamson notes, “[a] continuing challenge to transaction cost economics is to move beyond semiformal analysis of a reduced-form kind to do fully-formal analysis_-in the spirit of the work by Grossman and Hart (1986), but to place greater emphasis on plausible constructions” (1998: 50). Among the principle advantages of a more formal theory is that it forces researchers to define with greater precision the concepts that are central to the empirical analysis. Currently, a handful of core ideas in TCE suffer from multiple and, at times, competing definitions. For example, uncertainty is frequently defined as either environmental uncertainty, which references state-dependent changes in the circumstances surrounding exchange, or behavioral uncertainty, which references the strategic nondisclosure, disguise or distortion of relevant information. Unfortunately, transaction cost studies to date have yet to fully work out exactly how these two types of uncertainty affect organizational choice. Some researchers, for instance, have found that environmental uncertainty 
has a positive and significant effect on the vertical integration decision (Walker and Weber 1984; Anderson 1985; 1987; Anderson 1988). Other findings, however, cast doubt on this relationship (Anderson and Schmittlein 1984; Maltz 1994). Efforts to operationalize and define behavioral uncertainty have, likewise, encountered multiple, competing formulations. While a more complete formalization will not alleviate all definitional ambiguities, it should provide researchers with greater precision regarding the key concepts that are hypothesized to have organizational outcomes.

One added benefit of a more formal transaction cost economic theory is that is may allow researchers to fine tune the theory's existing predictions as well as develop and test new empirical implications. Perhaps TCE's greatest contribution to industrial organization has been a better understanding of the strong association between asset specificity and vertical integration. Further modeling of organizational choice within the TCE tradition may illuminate other factors that inform the vertical integration decision and governance choice more generally. To the extent that formalization allows scholars to generate more detailed and demanding empirical tests, it may also uncover evidence that is inconsistent with or directly contradictory to received TCE theory, thereby leading to further theoretical refinements (Whinston 2001). The formalization of transaction cost economics should provide a more thorough and precise understanding of how and why economic agents organize as they do.

\section{CONCLUSION}

This paper provides an extensive review and assessment of empirical work based in transaction cost economics (TCE) across a host of business- and non-business-related areas. The main goals of this paper are first, to provide a comprehensive review and assessment of empirical research in transaction cost economics across a variety of social sciences disciplines; and second, to examine the influence that transaction cost reasoning has had outside of the field of IO economics. A review of citations, articles and abstracts obtained from a variety of on-line and 
hardbound sources provided more than 600 articles that employ and empirically test some aspect of transaction cost economic theory.

We find considerable support overall in these articles for the main predictions of TCE. The empirical framework and insights of TCE have been utilized successfully by scholars to understand a variety of business-related phenomena in areas such as marketing, finance, international management, organizational behavior, strategy and innovation. More notable still is the extent to which transaction cost logic has been usefully applied in other social science disciplines, including law, political science, health economics and policy and agricultural economics and policy. Indeed, the shear breadth and volume of empirical work positions TCE as among the most influential intellectual perspectives emerging from the IO economics literature. To be sure, one must guard against overplaying the importance of the volume of extant empirical work utilizing a TCE framework. In fact, the quality of the existing empirical literature examined in this paper is variable, as are the strength of the conclusions of these papers. Moreover, the articles examined in this survey suggest that considerable work remains to more accurately assess and extend the core insights of TCE theory. We also find numerous theoretical gaps in the literature that still await empirical investigation. This survey nevertheless suggests that, relative to other major theoretical perspectives, there is little questioning the success of transaction cost economics not only in generating predictions that attempt to explain important organizational issues, but also in spawning tremendous interest among scholars and practitioners in a host of other disciplines outside of economics. 
1 Transaction cost economics (TCE) is sometimes described as the "governance” branch of the New Institutional Economics (NIE), as opposed to the measurement cost branch (Barzel 1982), agency-based branch (Grossman and Hart 1986; Hart and Moore 1990) or institutional environment branch (North 1990).

Other notable reviews include Lyons (1996), Masten and Saussier (2000) and Rindfleisch and Heide (1997). The number of empirical articles applying TCE arguments is a particularly noteworthy success story in the Industrial Organization (IO) economics literature; a field that is perhaps best known for the gulf that exists between theoretical and empirical work (Peltzman 1991). Paul Joskow (1991) echoes this sentiment, noting that work in TCE is "in much better shape than much of the empirical work in industrial organization generally.”

3 Shelanski and Klein's (1995) review is rather limited, with close to half of the authors' citations coming from just three economic journals: The Journal of Law and Economics, The Journal of Law, Economics and Organization and The Journal of Economic Behavior and Organization. Outside of marketing (Rindfleisch and Heide 1997), there have been limited systematic efforts to explore the extent to which TCE analysis has been incorporated in areas such as accounting, finance, organizational theory and business strategy.

4 The precise definition of what constitutes an "empirical test" of transaction cost economics is discussed in sub-section 2.3 .

$5 \quad$ See Simon (1957), Coase (1937), and Williamson (1996) for a more detailed treatment of bounded rationality.

6 Simple spot market transactions are said to be at one extreme, vertical integration at the other extreme, and a variety of hybrid forms are found in between (Williamson 1991).

$7 \quad$ Transaction cost economics further recognizes that different governance modes are supported by different legal regimes, ranging from contract law for market governance to employment law for hierarchy (Masten 1988; Williamson 1991). Market-based disputes between parties are either costlessly resolved by exiting the relationship or resolved with deference to classical contract law (MacNeil 1978). Hybrid forms of organization rely instead on neoclassical contract law and excuse doctrine, while hierarchies rely on forbearance (fiat), rather than legal recourse, to resolve disputes between and among parties.

$8 \quad$ We examine this exact issue in the section immediately below.

$9 \quad$ Although some studies incorporate continuous measures of the market and hierarchy continuum, including

Balakrishnan and Wernerfelt (1993), Gatignon and Anderson (1988), Hu and Chen (1993), John and Weitz (1988),

Klein (1989), Maltz (1993; 1994) and Masten, Meehan and Snyder (1989). 
Oliver Williamson (1996) identifies six types of asset specificity: (1) site, (2) physical asset, (3) human asset,

(4) dedicated assets, (5) brand name capital, and (6) temporal.

11 Rindfleisch and Heide (1997) note that other variations of the human asset specificity measure include Anderson and Schmittlein (1984); Heide and John (1988; 1990; 1992); John and Weitz (1988); Klein (1989); Klein and Roth (1990); Klein, Frazier and Roth (1990); Maltz (1993; 1994); Stumpe and Heide (1996); and Weiss and Anderson (1992).

12 Uncertainty related to environmental turbulence—including but not limited to complexity and volatility-is associated with more integrated governance structures, whilst uncertainty related to unpredictability—such as new technologies and volume-is associated with more market-like governance structures (Klein 1989)

13 The empirical TCE literature contains a number of excellent case studies. These include analyses of cable television franchising (Williamson 1976); organizational arrangements in the aluminum industry (Stuckey 1983), between rail operators and freight (Palay 1984), between tuna harvesters and processors (Gallick 1984), and between coal mines and electric utilities (Joskow 1985); contracts in the petroleum coke (Goldberg and Erickson 1987) and shoe (Masten and Snyder 1993) industries. Other case studies examine variations in ocean shipping contracts (Pirrong 1993), organizational arrangements in the French poultry industry (Menard 1996), the interaction of political institutions, regulatory processes and economic conditions for telecommunications regulation (Levy and Spiller 1994); divisional coordination problems created by technological interdependence (Argyres 1995), and the acquisition of Fisher Body by General Motors (Coase 2000; Klein 2000).

14 Examples in this category include Allen and Lueck’s (1998) analysis of farming; Galunic and Anderson’s

(2000) examination of firm-specific versus generalized investments in human capital in the North American insurance industry; Hubbard’s (2001) examination of hold-up in the U.S. for-hire trucking industry; and Pisano’s (1990a; 1990b) analysis of small-numbers bargaining hazards and appropriability concerns between in-house and external sources of R\&D in the biotechnology industry.

$15 \quad$ Examples in this category include Levy’s (1985), MacDonald’s (1985) and Caves and Bardburd’s (1988) examinations of vertical integration; Chi and Roehl's (1997) analysis of the structuring of interfirm exchanges for business know-how; Henisz (2000) examination of the choice of market entry and entry mode by multinational firms, Maher's (1997) examination of contractual relations between customers and suppliers; Murray and Kotabe’s (1999) analysis of sourcing strategies by Fortune 500 U.S. service firms and their major affiliates; and Taylor, Zou and Osland’s (1998) examination of multinational firms foreign market entry strategies. 
(2000), Masten et al. (1991), Nickerson et. al (2000), Poppo and Zenger (1998), Sampson (2006) and Saussier (2000).

17 The Contracting and Organizations Research Initiative (CORI) at the University of Missouri seeks to improve our understanding of how the economic system works by facilitating and enabling interdisciplinary empirical research on contracting and organizational structure. CORI is an interdisciplinary research group of faculty from such diverse backgrounds as economics, agriculture, finance, law, political science, and sociology. Information on the research activities at CORI can be found on http://cori.missouri.edu/.

18 Empirical work that examines contract design includes, but is not limited to, contract term issues such as price (Joskow 1988), royalty rates and franchise fees (Lafontaine 1992; Bercovitz 1999), take-or-pay provisions (Masten and Crocker 1985), price adjustment benefits (Crocker and Masten 1991; Crocker and Reynolds 1993), fixed versus variable payment schedules (Leffler and Rucker 1991; Masten and Snyder 1993), and dispute resolution (e.g., arbitration) mechanisms (McMillan and Woodruff 1999).

19 The actual number of published pieces is likely larger than that reported here since we are limited to published papers that are indexed in one of several on-line and hardbound sources. However, we caution readers that here, as elsewhere, these articles differ widely in quality. The stated amount is presented here only as an indicator of the continuing growth in empirical research in transaction cost economics, including its reach into and across social science disciplines.

20 These types are: physical asset, site, human asset, temporal specificity, brand name capital, and dedicated assets. For a more thorough discussion, see Williamson (1996: 58-60).

21 Similarly, a firm with high union density but no or limited relationship specific investments does not face this bargaining problem because the firm can opt to sell off the assets in the event of excess union wage demands. 22 See Lyons (1996) and Masten and Saussier (2000) for more thorough treatments of TCE-related empirical work in contracts.

$23 \quad$ Early examples of this type of analysis include Goldberg and Erickson's (1987) examination of the petroleum industry, Joskow's (1985; 1987; 1988; 1988; 1990) analyses on the duration of contracts between coal suppliers and electrical plants, Crocker and Masten's (1988; 1991) analyses of the design and duration of natural gas contracts, and Crocker and Reynold's (1993) examination of government procurement contracts for Air Force jet engines. 24 Complex product industries are those industries in which production processes involve a large number of components, functions and process steps. Examples include machine tools, robotics and consumer electronics, among others. 
See Liker et al. (1996), however, where alternative conclusions regarding differences in human cospecialization between the U.S. and Japan are found.

26 For an additional discussion of TCE empirical work in the marketing area, see Rindfleisch and Heide (1997) and Anderson (1996). Rindfleisch and Heide (1997) suggest that the large number of TCE-related empirical articles in marketing is also related to marketing's tradition in construct measurement and survey research techniques. These empirical approaches lend themselves to the operationalization and testing of important parts of the TCE framework. 27 Joshi and Stump (1999) recognize that their survey data suffer from two main problems. First, the data only include responses from one partner in the manufacturer-supplier dyad. Second, the study is cross-sectional in nature, but is used to make causal arguments.

28 It appears, however, that empirical activity in this area has accelerated in recent years, with thirteen empirical articles appearing in accounting journals since 2001.

29 Coase notes "[i]n understanding how in a competitive society the choice is made between these alternative but interrelated means of organization, we must take into account the role of the accounting system. The theory of the accounting system is part of the theory of the firm. It is not my belief that the secret to the determination of the institutional structure of production will alone be found in the accounting system, but it certainly contains part of the secret" (Coase 1990: 12).

30 Another means of diversification is geographic expansion or national banking. Geographic expansion may diversify risk since a large component of lending risk, especially real estate and agriculture, is regional in nature. $31 \quad$ Of particular interest in this regard are secondary and behavioral uncertainty. Secondary uncertainty arises from a general lack of communication between contracting parties and the inability of the parties to accurately assess each other's plans. Williamson $(1975 ; 1979 ; 1981)$ points out that uncertainty may also arise from more strategic behavior on the part of actors. He refers to efforts by economic agents to disguise and distort information as "behavioral" uncertainty.

32 See Barton, et al. (1999), Hannan, et al. (1999), and Carroll and Teo (1999) as excellent examples of organizational theory research that makes use of transaction cost economic theory.

33 See, for example, DiMaggio and Powell (1991) and Meyer and Rowan (1994).

34 The debate between the explanatory power of TCE and organization theory runs both ways. Shelanski (2004), for example, argues that Eccles and White (1988) have a truncated understanding of transaction cost economics in terms of transfer pricing. A healthy and ongoing dialogue should therefore prove beneficial to both theories. 35 The interaction of country risk and asset specificity provided no explanatory power to their model, and was thus not included in their analysis. Sociocultural distance did not have a significant impact on governance choice. 
It may be that intermediate levels involve complex adjustments and safeguard mechanisms to make sure that the subsidiary runs smoothly and that the interests of the involved parties are protected. These factors are likely not being captured in this relatively simple model.

37 The performance implications of relationship specific investment and performance is further explored in Anderson, et al. (1998).

38 In the former case, licensing contracts are difficult to write and enforce due to the tacit nature of the resource being contracted for. In the latter case, attempts to negotiate a licensing contract are plagued by problems of appropriating the returns to technology.

$39 \quad$ See especially Crocker and Masten (1996) and Joskow (1988) for a partial review of this literature.

40 First, the regulatory system places restraints on regulators. Second, political and judicial systems place restraints on the regulatory system. Third, there exist institutions for enforcing restraints on regulators and policing efforts to change the structure of the system.

$41 \quad$ In pulling together articles for this review, many more unpublished pieces applying transaction cost reasoning were discovered. Casual observation suggests that this is an increasingly important forum for the empirical application of transaction cost reasoning.

42 This study is broadly consistent with Walker and Weber's (1987) earlier examination of integration in the supply of component parts to the automobile industry, where product uncertainty, when coupled with "thin" supply markets, is found to increase the probability that a component will be made in-house.

43 Masten (2000) provides a thorough review of the logic, hypotheses, empirical methods and principal findings of the transaction cost approach to economic organization as it applies to agricultural transactions. This section borrows from his survey. 


\section{REFERENCES}

Adler, T. R., R. F. Scherer, S. L. Barton and R. Katerberg (1999). “An Empirical Test of

Transaction Cost Theory: Validating Contract Typology.” Journal of Applied

Management Studies 7(2): 185-200.

Ahmadjian, C.L. and J.E. Oxley (2006). "Using Hostanges to Support Exchange: Dependence

Balancing and Partial Equity Stakes in Japanese Automotive Supply Relationships."

Journal of Law, Economics, and Organization 22(1): 213-233.

Alger, D. and M. Toman (1990). “Market-Based Regulation of Natural Gas Pipelines.” Journal of Regulatory Economics 2: 263-280.

Allen, D. W. and D. Lueck (1992a). "The "Back Forty" on a Handshake: Specific Assets, Reputation and the Structure of Farmland.” Journal of Law, Economics and Organization 8(2): 366-76.

Allen, D. W. and D. Lueck (1992b). "Contract Choice in Modern Agriculture: Cash Rent Versus Cropshare.” Journal of Law and Economics 35(2): 397-426.

Allen, D. W. and D. Lueck (1993). “Transaction Costs and the Design of Cropshare Contracts.” RAND Journal of Economics 21(1): 78-100.

Allen, D. W. and D. Lueck (1996). The Transaction Cost Approach to Agricultural Contracts. Agricultural Markets: Mechanisms, Failures and Regulations. D. Martimort. Amsterdam, Elsevier Science.

Allen, D. W. and D. Lueck (1998). “The Nature of the Farm.” Journal of Law, Economics and Organization 41: 343-386.

Allen, D.W. and D. Lueck (2000). "A Transaction Cost Primer on Farm Organization." Canadian Journal of Agricultural Economics 48(4): 643-52.

Allen, J. and G. Phillips (2000). "Corporate Equity Ownership, Strategic Alliances, and Product Market Relationships." Journal of Finance 55(6): 2791-2815. 
Alston, L. J. and R. Higgs (1982). “Contractual Mix in Southern Agriculture Since the Civil War: Hypotheses and Tests.” Journal of Economic History 42.

Alt, J. E., F. Carlsen, P. Heum and K. Johansen (1999). “Asset Specificity and the Political Behavior of Firms: Lobbying for Subsidies in Norway.” International Organization 53(1): 99-116.

Anderson, E. (1985). “The Salesperson as Outside Agent or Employee: A Transaction Cost Analysis.” Marketing Science 4: 234-254.

Anderson, E. (1988). “Transaction Costs as Determinants of Opportunism in Integrated and Independent Sales Forces.” Journal of Economic Behavior and Organization 9: 247-264.

Anderson, E. (1996). Transaction Cost Analysis and Marketing. Transaction Cost Economics and Beyond. J. Groenewegen. Boston, Kluwer Academic Press.

Anderson, E. and A. T. Coughlan (1987). “International Market Entry and Expansion Via Independent or Integrated Channels of Distribution.” Journal of Marketing 51: 71-82.

Anderson, E., W. T. Ross and B. Weitz (1998). “Commitment and its Consequences in the American Agency System of Selling Insurance.” Journal of Risk and Insurance 65(4): 637-69.

Anderson, E. and D. C. Schmittlein (1984). “Integration of the Sales Force: an Empirical Examination.” RAND Journal of Economics 15(3): 385-395.

Anderson, E. and B. A. Weitz (1992). “The Use of Pledges to Build and Sustain Commitment in Distribution Channels.” Journal of Marketing Research 29(February): 18-34.

Argyres, N. S. (1995). “Technology Strategy, Governance Structure and Interdivisional Coordination.” Journal of Economic Behavior and Organization 28: 337-358.

Argyres, N. S. (1996). “Capabilities, Technological Diversification and Divisionalization.” Strategic Management Journal 17: 395-410.

Arrighetti, A., R. Bachmann and S. Deakin (1997). “Contract Law, Social Norms and Inter-firm Cooperation.” Cambridge Journal of Economics 21(2): 171-95. 
Artz, K. W. and T. H. Brush (2000). “Asset specificity, uncertainty and relational norms: an examination of coordination costs in collaborative strategic alliances.” Journal of Economic Behavior and Organization 42(4): 337-362.

Ashton, T. (1998). “Contracting for Health Services in New Zealand: A Transaction Cost Analysis.” Social Science Medicine 46(3): 357-367.

Aubert, B. A., S. Rivard and M. Patry (1996). “A Transaction Cost Approach to Outsourcing Behavior: Some Empirical Evidence.” Information and Management 30(2): 51-64.

Baker, G. R. and R. B. Chapman (1989). “Evaluating Labor Market Contracting and Regulation: A Transaction Costs Perspective with Particular Reference to New Zealand.” Journal of Institutional and Theoretical Economics 145: 317-42.

Balakrishnan, S. and I. Fox (1993). “Asset Specificity, Firm Heterogeneity, and Capital Structure.” Strategic Management Journal 14: 3-16.

Balakrishnan, S. and B. Wernerfelt (1986). “Technical Change, Competition and Vertical Integration.” Strategic Management Journal 7: 347-359.

Baranoff. E. and Thomas Sager (2002). "The Relations among Asset Risk, Product Risk, and Capital in the Life Insurance Industry." Journal of Banking \& Finance 26(6): 1181-1197. Baranoff E. and Thomas Sager (2003). "The Relations among Organizational and Distributional Forms an Capital and Asset Risk Structures in the Life Insurance Industry." Journal of Risk and Insurance 70: 375-400.

Bariletti, A. and G. France (1996). “Transaction Cost Economics and Efficiency in Health Reform: The Case of Italy.” Dipartmento di Scienze Economiche, Studi e Discussioni: Universita di Fireze 103.

Barton, J. N., M. D. Burton and M. T. Hannan (1999). The Road Taken: Origins and Evolution of Employment Systems in Emerging Companies. Firms, Markets and Hierarchies. G. R. Carroll and D. J. Teece. New York, Oxford University Press. 
Barzel, Y. (1982). “Measurement Cost and the Organization of Markets.” Journal of Law and Economics 25(April): 27-48.

Bazzoli, G.J., B. Chan, S.M. Shortell, and T. D'Aunno (2000). "The Financial Performance of Hospitals Belonging to Health Networks and Systems." Inquiry: The Journal of Health Care Organization, Provision and Financing 37(3): 234-52.

Beatty, A., K. Ramesh and J. Weber (2002). "The Importance of Accounting Changes in Debt Contracts." Journal of Accounting \& Economics 33: 205-227.

Bensaou, B. M. and E. Anderson (1999). “Buyer-Supplier Relations in Industrial Markets: When Do Buyers Enter the Trap of Making Idiosyncratic Investments?” Organization Science 10(4): 460-481.

Bercovitz, J. E. L. (1999). A Refined Empirical Test of the Choice of Ownership Mode in Business-Format Franchising. Haas School of Business. Berkeley, University of California, Berkeley.

Bergara, M. E., W. J. Henisz and P. T. Spiller (1998). "Political Institutions and Electric Utility Investment: A Cross-National Analysis.” California Management Review 40(2): 18-35.

Bergh, D. and M. Lawless (1998). "Portfolio Restructuring and Limits to Hierarchical Governance: Effects of Environmental Uncertainty and Diversification Strategy.” Organization Science 9(1): 87-102.

Bertero, E. (1997). “Restructuring Financial Systems in Transition and Developing Economies: An Approach Based on the French Financial System.” Economics of Transition 5(2): 367-393.

Bethel, J. E. and J. P. Liebeskind (1998). “Diversification and the Legal Organization of the Firm.” Organization Science 9(1): 49-67.

Bigelow, L. (2001). Efficient Alignment and Survival in the U.S. Automobile Industry. St. Louis, MO, Washington University Olin School of Business. 
Bindseil, U. (1997). "Vertical Integration in the Long Run: The Provision of Physical Assets to the London and New York Stock Exchanges.” Journal of Institutional and Theoretical Economics 153: 641-56.

Bjuggren, P. O. (1995). “A Transaction Cost Perspective on Financial Distress and Capital Structure.” International Review of Law and Economics 15(4): 395-404.

Brickley, J. A. (1999). “Incentives, Conflicts and Contractual Restraints: Evidence from Franchising.” Journal of Law and Economics 42(2): 745-74.

Brouthers, K. D. and L. E. Brouthers (2000). “Acquisition or Greenfield Start-up? Institutional, Cultural and Transaction Cost Influences.” Strategic Management Journal 21(1): 89-97.

Brown, J. H. and M. Partridge (1998). “The Death of a Market: Standard Oil and the Demise of the 19th Century Crude Oil Exchanges.” Review of Industrial Organization 13(5).

Brown, J. R. and C. S. D. a. D. J. Lee (2000). “Managing Marketing Channel Opportunism: The Efficacy of Alternative Governance Mechanisms.” Journal of Marketing 64(2): 51-65.

Bucklin, L. P. and S. Sengupta (1993). “Organizing Successful Co-Marketing Alliances.” Journal of Marketing 57(April): 32-46.

Buvik, A. and G. John (2000). "When Does Vertical Coordination Improve Industrial Purchasing Relationships?” Journal of Marketing 64: 52-64.

Buvik, A. and T. Reve (2001). "Assymmetrical Deployment of Specific Assets and Contractual Safeguarding in Industrial Purchasing Relationships." Journal of Business Research 51: 101-113.

Cameron, S. and A. Collins (1997). "Transaction Costs and Partnerships: The Case of Rock Bands.” Journal of Economic Behavior and Organization 32: 171-183.

Carr, J. and J. T. Landa (1983). “The Economics of Symbols, Clan Names, and Religion” Journal of Legal Studies 12(1). 
Carroll, G. R., P. T. Spiller and D. J. Teece (1999). Transaction Cost Economics: Its Influence on Organizational Theory, Strategic Management, and Political Economy. Firms, Markets and Hierarchies. G. R. Carroll and D. J. Teece. New York, Oxford University Press.

Carroll, G. R. and A. C. Y. Teo (1999). Creative Self-Destruction Among Organizations. Firms, Markets and Hierarchies. G. R. Carroll and D. J. Teece. New York, Oxford University Press.

Casciaro, T. (2003). "Determinants of Governance Structure in Alliances: the Role of Strategic, Task, and Partner Uncertainties." Industrial and Corporate Change 12(6): 1223.

Cavanaugh, J. K. (1998). “Asset-Specific Investment and Unionized Labor.” Industrial Relations 37(1): 35-50.

Caves, R. E. and R. E. Bradburd (1988). “The Empirical Determinants of Vertical Integration.” Journal of Economic Behavior and Organization 9: 265-279.

Che, J. and Y. Qian (1998). “Institutional Environment, Community Government, and Corporate Governance: Understanding China's Township-Village Enterprises.” Journal of Law, Economics and Organization 14(1): 1-23.

Chi, T. and T. W. Roehl (1997). “The Structuring of Interfirm Exchanges in Business KnowHow: Evidence from International Collaborative Ventures.” Managerial and Decision Economics 18: 279-294.

Choi, C. J., S. H. Lee and J. B. Kim (1999). “A Note on Countertrade: Contractual Uncertainty and Transaction Governance in Emerging Economies.” Journal of International Business Studies 30(1): 189-202.

Ciccotello, C. S., M. J. Hornyak, and M. S. Piwowar. "Research and Development Alliances: Evidence from a Federal Contracts Repository." Journal of Law and Economics 47(1): 123-166.

Coase, R. H. (1937). “The Nature of the Firm.” Econometrica(November). 
Coase, R. H. (1990). “Accounting and the Theory of the Firm.” Journal of Accounting and Economics 12: 3-13.

Coase, R. H. (2000). “The Acquisition of Fisher Body By General Motors.” Journal of Law and Economics 43: 15-30.

Coff, R. (2003). "Bidding Wars Over R\&D-Intensive Firms: Knowledge, Opportunism, and the Market for Corporate Control." Academy of Management Journal 46(1): 74-85.

Coles, J. and W. S. Hesterly (1998). “The Impact of Firm-Specific Assets and the Interaction of Uncertainty: An Examination of Make or Buy Decisions in Public and Private Hospitals.” Journal of Economic Behavior and Organization 36: 383-409.

Cooke, W. (1997). “The Influence of Industrial Relations Factors on U.S. Foreign Direct Investment Abroad.” Industrial and Labor Relations Review 50(1): 3-17.

Cooper, R. and R. Slagmulder (2004). "Interorganizational Cost Management and Relational Context." Accounting Organizations and Society 29: 1-26.

Crocker, K. J. and S. E. Masten (1988). “Mitigating Contractual Hazards: Unilateral Options and Contract Length.” RAND Journal of Economics 19: 327-343.

Crocker, K. J. and S. E. Masten (1991). “Pretia Ex Machina? Prices and Process in Long-Term Contracts.” Journal of Law and Economics 23: 69-99.

Crocker, K. J. and S. E. Masten (1996). “Regulation and Administered Contracts Revisited: Lessons from Transaction-Cost Economics for Public Utility Regulation.” Journal of Regulatory Economics 9: 5-39.

Crocker, K. J. and K. J. Reynolds (1993). “The Efficiency of Incomplete Contracts: An Empirical Analysis of Air Force Engine Procurement.” RAND Journal of Economics 24: 126-146. Dahl, C. A. and T. K. Matson (1998). "Evolution of the US Natural Gas Industry in Response to Changes in Transaction Costs.” Land Economics 74(3): 390-408.

Dansky, K. (1996). “Understanding Hospital Referrals to Home Health Agencies.” Hospital \& Health Services Administration 41(3): 331-342. 
Datta, S. and J. O. H. K. Donald, and J. Nugent (1986). “Choice of Agricultural Tenancy.” Land Economics 62.

DeBruin, A. and A. Dupuis (1999). “Toward a Synthesis of Transaction Cost Economics and a Feminist Oriented Network Analysis: An Application to Women's Street Commerce.” American Journal of Economics and Sociology 58(4).

de Figueiredo, J.M. and J.J. Kim (2004). "Why Do Firms Hire Lobbyists? The Organization of Lobbying at the Federal Communications Commission." Industrial and Corporate Change 13(6): 883-900.

Delmas, M. and A. Marcus (2004). " Firms' Choice of Regulatory Instruments to Reduce Pollution: A Transaction Cost Approach." Business and Politics 6(3): 1-20.

Delois, A. and W. J. Henisz (2000). “Japanese Firms' Investment Strategies in Emerging Economies.” Academy of Management Journal 43(3): 305-323.

DiMaggio, P. J. and W. W. Powell (1991). The New Institutionalism in Organizational Analysis. Chicago, University of Chicago Press.

Dixit, A. K. (1996). The Making of Economic Policy: A Transaction-Cost Politics Perspective. Boston, MA, MIT Press.

Doh, J.P., H. Teegen, and R. Mudambi. "Balancing Private and State Ownership in Emerging Markets' Telecommunications Infrastructure." Journal of International Business Studies 35(3): 233-250.

Dutta, S. and G. John (1995). “Combining Lab Experiments and Industry Data in Transaction Cost Analysis: The Case of Competition as a Safeguard.” Journal of Law, Economics and Organization 11(1): 87-111.

Dyer, J. H. (1996). “Does Governance Matter? Keiretsu Alliances and Asset Specificity as Sources of Japanese Competitive Advantage.” Organization Science 7. 
Dyer, J.H. and W.J. Chu. (2003). "The Role of Trustworthiness in Reducing Transaction Costs and Improving Performance: Empirical Evidence from the United States, Japan, and Korea." Organization Science 14(1): 57-68.

Eccles, R. G. and H. C. White (1988). "Price and Authority in Inter-Profit Center Transactions.” American Journal of Sociology 94: S17-S51.

Elfenbein, D.W. and J. Lerner (2003). "Ownership and Control Rights in Internet Portal Alliances." Rand Journal of Economics 34(2): 356-369.

Erramilli, M. and C. P. Rao (1993). “Service Firms' International Entry Mode Choice: A Modified Transaction Cost Approach.” Journal of Marketing 57(July): 19-38.

Erridge, A., R. Fee and J. Mcilroy (1999). “An Assessment of Competitive Tendering Using Transaction Cost Analysis.” Public Money and Management 19(3): 37-42.

Fisher, L.M. (2004). "The Wealth Effects of Sale and Leasebacks: New Evidence." Real Estate Economics 32(4): 619-643.

Fein, A. J. and E. Anderson (1997). “Patterns of Credible Commitments: Territory and Brand Selectivity in Industrial Distribution Channels.” Journal of Marketing 61(2): 19-34.

Frank, S. D. and D. R. Henderson (1992). “Transaction Costs as Determinants of Vertical Coordination in the U.S. Food Industries.” American Journal of Agricultural Economics 74: 941-950.

Freeland, R. F. (1996). “The Myth of the M-Form? Governance, Consent, and Organizational Change.” American Journal of Sociology 102(2): 483-526.

Freeman, J., G. R. Carroll and M. T. Hannan (1983). “The Liability of Newness: Age Dependence in Organizational Death Rates.” American Sociological Review 48: 692-710.

Gallick, E. (1996). Exclusive Dealing and Vertical Integration: The Efficiency of Contracts in the Tuna Industry. Case Studies in Contracting and Organization. S. Masten. New York, Oxford. 
Gallick, E. C. (1984). Exclusive Dealing and Vertical Integration: The Efficiency of Contracts in the Tuna Industry. Washington, DC., Federal Trade Commission, Bureau of Economics.

Galunic, D. C. and E. Anderson (2000). “From Security to Mobility: Generalized Investments in Human Capital and Agent Commitment.” Organization Science 11(1): 1-20.

Gatignon, H. and E. Anderson (1988). “The Multinational Corporation's Degree of Control Over Foreign Subsidiaries: An Empirical Test of a Transaction Cost Explanation.” Journal of Law, Economics, and Organization 4: 305-336.

Globerman, S. and R. Schwindt (1986). “The Organization of Vertically Related Transactions in the Canadian Forest Products Industries.” Journal of Economic Behavior \& Organization $7(2)$.

Goedecke, E. J. and G. F. Ortmann (1993). “Transaction Costs and Labour Contracting in the South African Forestry Industry.” South African Journal of Economics 61(1): 67-83.

Goldberg, V. B. (1976). "Regulation and Administered Contracts.” Bell Journal of Economics 7(2): 426-448.

Goldberg, V. P. and J. R. Erickson (1987). “Quantity and Price Adjustment in Long-Term Contracts: A Case Study of Petroleum Coke.” Journal of Law and Economics 30(October): 369-98.

Gomes-Casseres, B. (1989). “Ownership Structures of Foreign Subsidiaries: Theory and Evidence.” Journal of Economic Behavior and Organization 11: 1-25.

Gonzalez-Diaz, M., B. Arrunada and A. Fernandez (2000). “Causes of Subcontracting: Evidence from Panel Data on Construction Firms.” Journal of Economic Behavior and Organization 42(2): 167-187.

Grandy, C. (1989). “Can Government Be Trusted to Keep Its Part of a Social Contract? New Jersey and the Railroads, 1825-1888.” Journal of Law, Economics and Organization 5 : 249-69. 
Granovetter, M. (1985). “Economic Action and Social Structure: The Problem of Embeddedness.” American Journal of Sociology 91(November): 481-510.

Grossman, S. J. and O. D. Hart (1986). “The Costs and Benefits of Ownership: A Theory of Vertical and Lateral Integration.” Journal of Political Economy 94(August): 691-719.

Gulati, R. and H. Singh (1998). “The Architecture of Cooperation: Managing Coordination Costs and Appropriation Concerns in Strategic Alliances.” Administrative Science Quarterly 43(4): 781-814.

Hamilton, H. (1999). "Property Rights and Transaction Costs in Marriage: Evidence from Prenuptial Contracts.” The Journal of Economic History 59(1): 68-103.

Hannan, M. T., M. D. Buron and J. N. Baron (1999). Inertia and Change in the early Years. Firms, Markets and Hierarchies. G. R. Carroll and D. J. Teece. New York, Oxford University.

Hannan, M. T. and J. Freeman (1984). Organization Ecology. Cambridge, MA, Harvard University Press.

Harrigan, K. R. (1986). “Matching Vertical Integration Strategies to Competitive Conditions.” Strategic Management Journal 7: 535-555.

Harris, D.G. and J.R. Livingstone (2002). "Federal Tax Legislation as an Implicit Contracting Cost Benchmark." Accounting Review 77: 997-1018.

Hart, O. (1995). Firms Contracts and Financial Structure. Oxford, UK, Clarendon Press.

Hart, O. D. and J. Moore (1990). “Property Rights and the Nature of the Firm.” The Journal of Political Economy 98(6): 1119-1158.

Heide, J. B., S. Dutta and M. Bergen (1998). “Exclusive Dealing and Business Efficiency: Evidence From Industry Practice.” Journal of Law and Economics 41(2): 387-407. Heide, J. B. and G. John (1988). “The Role of Dependence Balancing in Safeguarding Transaction-Specific Assets.” Journal of Marketing 52: 20-35. 
Heide, J. B. and G. John (1990). “Alliances in Industrial Purchasing: The Determinants of Joint Action in Buyer-Supplier Relationships.” Journal of Marketing Research 27(1): 24-36. Heide, J. B. and G. John (1992). “Do Norms Matter in Relationship Marketing.” Journal of Marketing 56(2): 32-45.

Helfat, C. and D. J. Teece (1987). “Vertical Integration and Risk Reduction.” Journal of Law, Economics and Organization 3: 47-67.

Henisz, W. J. (1998). The Institutional Environment for International Investment: Safeguarding Against State Sector Opportunism and Opportunistic Use of the State. Walter A. Haas

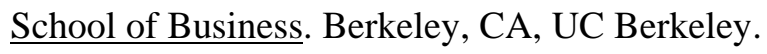

Henisz, W. J. (2000). “The Institutional Environment for Multinational Investment.” Journal of Law, Economics, and Organization 16(2): 334-364.

Henisz, W.J. (2002). Politics and International Investment (Elgar Publishing: London).

Henisz, W. J. and B. A. Zelner (2001). “The Institutional Environment for Telecommunications Investment.” Journal of Economics and Management Strategy 10(1).

Hill, C. W. (1988). “Internal Capital Market Controls and Financial Performance in Multidivisional Firms.” Journal of Industrial Economics 37(1): 67-83.

Hobbs, J. (2003). "Information, Incentives and Institutions in the Agri-Food Sector." Canadian Journal of Agricultural Economics 51(3):413-30.

Hodgkin, D., Constance M. Horgan and D. W. Garnick (1997). “Make or Buy: HMOs' Contracting Arrangement for Mental Health Care.” Administration and Policy in Mental Health 24(4): 359-376.

Hoetker, G. (2005). "How Much You Know versus How Well I Know You: Selecting a Supplier for a Technically Innovative Component." Strategic Management Journal 26(1): 75-96.

Hu, M. and H. Chen (1993). “Foreign Ownership in Chinese Joint Ventures.” Journal of Business Research 26(2): 500-513. 
Hubbard, T. N. (2001). "Contractual Form and Market Thickness in Trucking." Rand Journal of Economics 32(2): 369-386.

Hughes, D., Lesley Griffiths and J. V. McHale (1997). “Do Quasi-Markets Evolve? Institutional Analysis and the NHS.” Cambridge Journal of Economics 21: 259-276.

Husted, B. W. (1994). “Transaction costs, norms and social networks.” Business \& Society 33(1 (Apr)): 30-57.

Inderst, R. and H.M. Muller (2003). "Internal Versus External Financing: An Optimal Contracting Approach." Journal of Finance 58: 1033-1062.

Jensen, J. B. and G. S. Rothwell (1998). “Transaction Costs, Regulation, and Subcontracting at Nuclear Power Plants.” Journal of Economic Behavior and Organization 36: 369-381. Jensen, M. and W. Meckling (1976). “Rights and Production Functions.” Journal of Business 52(October): 496-506.

John, G. and B. A. Weitz (1988). “Forward Integration into Distribution: An Empirical Test of Transaction Cost Analysis.” Journal of Law, Economics and Organization 4: 337-355. John, G. and B. A. Weitz (1989). “Salesforce Compensation: An Empirical Investigation of Factors Related to Use of Salary Versus Incentive Compensation.” Journal of Marketing Research 26(February): 1-14.

Jones, P. and J. Hudson (1998). “The Role of Political Parties: An Analysis Based on Transaction Costs.” Public Choice 94: 175-189.

Joshi, A. W. and R. L. Stump (1999). “The contingent effect of specific asset investments on joint action in manufacturer-supplier relationships: An empirical test of the moderating role of reciprocal asset investments, uncertainty, and trust.” Academy of Marketing Science 27(3): 291-305.

Joskow, P. (1985). "Vertical Integration and Long-Term Contracts: The Case of Coal-Burning Electric Generating Plants.” Journal of Law, Economics, and Organization 1(Spring): 3380. 
Joskow, P. (1987). “Contract Duration and Relation Specific Investments: Empirical Evidence from Coal Markets.” American Economic Review 17(March): 168-85.

Joskow, P. (1991). “The Role of Transaction Cost Economics in Antitrust and Public Utility Regulatory Policies.” Journal of Law, Economics and Organization 7(Special Issue): 5383.

Joskow, P. (1996). “Introducing Competition into Regulated Network Industries: From Hierarchies to Markets in Electricity.” Industrial and Corporate Change 5(2): 341-382.

Joskow, P. L. (1988). “Asset Specificity and the Structure of Vertical Relationships: Empirical Evidence.” Journal of Law, Economics, and Organization 4(1): 95-117.

Joskow, P. L. (1988). “Price Adjustment in Long-Term Contracts: The Case of Coal.” Journal of Law and Economics 31: 47-83.

Joskow, P. L. (1990). “The Performance of Long-Term Contracts: Further Evidence from the Coal Markets.” RAND Journal of Economics 21: 251-274.

Joskow, P.L. (2002). "Transaction Cost Economics, Antitrust Rules, and Remedies." Journal of Law, Economics, and Organization 18(1): 95-116.

Kashlak, R., R. Cahandran and C. A. Di Benedetto (1998). “Reciprocity in International Business: A Study of Telecommunications Alliances and Contracts.” Journal of International Business Studies 29(2): 281-304.

Kaufman, P. and F. Lafontaine (1994). "Costs of Control: The Source of Economic Rents for McDonalds Franchisees.” Journal of Law and Economics 37: 417-453.

Kavanagh, I. and D. Parker (1999). "Managing the Contract: A Transaction Cost Analysis of Externalization." Local Government Studies 26 (4): 1-22.

Kim, K. (1999). “On Determinants of Joint Action in Industrial Distributor-Supplier Relationships: Beyond Economic Efficiency.” International Journal of Research in Marketing 16(3): 217-236. 
Klein, B. (2000). “Fisher-General Motors and the Nature of the Firm.” Journal of Law and Economics 43: 105-141.

Klein, B., R. G. Crawford and A. A. Alchian (1978). "Vertical Integration, Appropriable Rents, and the Competitive Contracting Process.” Journal of Law and Economics 21(October): 297-326.

Klein, S. (1989). “A Transaction Cost Explanation of Vertical Control in International Markets.” Journal of the Academy of Marketing Science 17: 530-560.

Klein, S., G. L. Frazer and V. J. Roth (1990). “A Transaction Cost Analysis Model of Channel Integration in International Markets.” Journal of Marketing Research 27: 196-208.

Klein, S. and V. J. Roth (1990). "Determinants of Export Channel Structure: The Effects of Experience and Psychic Distance Reconsidered.” International Marketing Review 7(5): 27-38.

Klein, S. and V. J. Roth (1993). “Satisfaction With International Marketing Channels.” Journal of the Academy of Marketing Science 29(Winter): 39-44.

Knoeber, C. (1983). “An Alternative Mechanism to Assure Contractual Reliability.” Journal of Legal Studies 12: 333-343.

Lafontaine, F. (1992). “Agency Theory and Franchising: Some Empirical Results.” RAND Journal of Economics 23: 263-283.

Lajili, K., Peter J. Barry, Steven T. Sonka and J. T. Mahoney (1997). “Farmers' Preferences for Crop Contracts.” Journal of Agricultural and Resource Economics 22(2): 264-280.

Landa, J. T. (1981). “A Theory of the Ethnically Homogenous Middleman Group: An Institutional Alternative to Contract Law” Journal of Legal Studies 10(2).

Landa, J. T. (1988). “Underground Economies: Generic or Sui Generis?” in Jerry Jenkins (ed.) BEYOND THE INFORMAL SECTOR: INCLUDING THE EXCLUDED IN DEVELOPING ECONOMIES (ICS Press).

Landa, J. T. (1994). Trust, Ethnicity, and Identity (Univ. of Michigan Press). 
Larue, B., J. Gervais, and H.E. Lapan. (2004). "Low-Price Low-Capacity Traps and Government Intervention in the Quebec Hog Market." Canadian Journal of Agricultural Economics 52(3): 237-56.

Lee, K.S., G.H. Lim and W.S. Lim (2003). "Family Business Succession: Appropriation Risk and Choice of Successor." Academy of Management Review 28(4): 657-666.

Leffler, K. and R. Rucker (1991). “Transaction Costs and the Efficient Organization of Production: A Study of Timber-Harvesting Contracts.” Journal of Political Economy 99(October): 1060-1087.

Lehrman, S. and K. K. Shore (1998). “Hospitals' Vertical Integration into Skilled Nursing: A Rational Approach to Controlling Transaction Costs.” Inquiry 35: 303-314.

Levy, B. and P. T. Spiller (1994). “The Institutional Foundations of Regulatory Commitment: A Comparative Analysis of Telecommunications Regulation.” Journal of Law, Economics and Organization 10(2): 201-246.

Levy, D. (1985). “The Transaction Cost Approach to Vertical Integration: An Empirical Examination.” Review of Economics and Statistics 67: 438-445.

Libecap, G. D. and J. L. Smith (1999). “The Self Enforcing Provision of Oil and Gas Unit Operating Agreements: Theory and Evidence.” Journal of Law, Economics, and Organization 15(2): 526-548.

Lieberman, M. B. (1991). “Determinants of Vertical Integration: An Empirical Test.” Journal of Industrial Economics 39: 451-466.

Liker, J. K., R. R. Kamath, S. N. Wasti and M. Nagamachi (1996). “Supplier Involvement in Automotive Component Design: Are There Really Large US Japan Differences?” Research Policy 25(1): 59-89.

Lyons, B. R. (1995). “Specific Investment, Economies of Scale, and the Make-or-Buy Decision: A Test of Transaction Cost Theory.” Journal of Economic Behavior and Organization 26: 431-433. 
Lyons, B. R. (1996). "Empirical Relevance of Efficient Contract Theory: Inter-Firm Contracts.” Oxford Review of Economic Policy 12(4): 27-52.

MacDonald, J. M. (1985). “Market Exchange or Vertical Integration: An Empirical Analysis.” Review of Economics and Statistics 67: 327-331.

Macher, J. T. (2000). Vertical Disintegration and Process Innovation in Semiconductor Manufacturing: Foundries vs. Integrated Producers. McDonough School of Business Working Paper, Georgetown University.

MacNeil, I. R. (1978). “Contracts: Adjustments of Long-Term Economic Relations Under Classical, Neoclassical and Relational Contract Law.” Northwestern University Law Review 72: 854-906.

Maher, M. E. (1997). “Transaction Cost Economics and Contractual Relations.” Cambridge Journal of Economics 21: 147-170.

Maltz, A. (1993). “Private Fleet Use: A TC Approach.” Transportation Journal 32: 46-53.

Maltz, A. (1994). “Outsourcing the Warehousing Function.” Logistics and Transportation Review 30: 245-65.

Masten, S. E. (1984). “The Organization of Production: Evidence from the Aerospace Industry.” Journal of Law and Economics 27: 403-417.

Masten, S. E. (1988). “A Legal Basis for the Firm.” Journal of Law, Economics and Organization 4(Spring): 181-98.

Masten, S. E. (1993). “Transaction Costs, Mistakes, and Performance: Assessing the Importance of Governance.” Managerial and Decision Economics 14: 119-129.

Masten, S. E. (2000). “Transaction-Cost Economics and the Organization of Agricultural Transactions.” Industrial Organization 9: 173-195.

Masten, S. E. and K. J. Crocker (1985). “Efficient Adaptation in Long-Term Contracts: Take-orPay Provisions for Natural Gas.” American Economic Review 75: 1083-1093. 
Masten, S. E., J. Meehan and E. Snyder (1991). “The Costs of Organization.” Journal of Law, Economics and Organization 7(1-25).

Masten, S. E., J. W. Meehan and E. A. Snyder (1989). "Vertical Integration in the U.S. Auto Industry: A Note on the Influence of Specific Assets.” Journal of Economic Behavior and Organization 12: 265-273.

Masten, S. E. and S. Saussier (2000). "Econometrics of Contracts: An Assessment of Developments in the Empirical Literature on Contracting.” Revue d'Economie Industrielle 0(92): 215-36.

Masten, S. E. and E. A. Snyder (1993). “United States Versus United Shoe Machinery Corporation: On the Merits.” Journal of Law and Economics 36(33-70).

Matthews, R. C. O. (1986). “The Economics of Institutions and the Sources of Economic Growth.” Economic Journal 96(December): 903-18.

McMillan, J. and C. Woodruff (1999). “Dispute Prevention Without Courts in Vietnam.” Journal of Law, Economics and Organization 15(3): 637-658.

Menard, C. (1996). “On Clusters, Hybrids and Other Strange Forms: The Case of the French Poultry Industry.” Journal of Institutional and Theoretical Economics 152.

Menard, C. and M. Shirley (2000). Reforming Urban Water Systems Within Different Institutional Environments.

Meyer, J. and B. Rowan (1994). “Institutional Organizations: Formal Structure as Myth and Ceremony.”.

Minkler, A. and T. Park (1994). “Asset Specificity and Vertical Integration in Franchising.” Review of Industrial Organization 9(4).

Moe, T. M. (1990). The Politics of Structural Choice: Toward a Theory of Public Bureaucracy. Organization Theory: From Chester Barnard to the Present and Beyond. O. E. Williamson. 
Mohrman, M. B. (1992). Debt Contracts and FAS 19: A Test of the Debt Covenant Hypothesis. St. Louis, Missouri, University of Missouri-St. Louis.

Mohrman, M. B. (1996). “The Use of Fixed GAAP Provisions in Debt Contracts.” Accounting Horizons 10(3): 78-91.

Monteverde, K. (1995). “Technological Dialog as an Incentive for Vertical Integration in the Semiconductor Industry.” Management Science 41(10): 1624-1638.

Monteverde, K. and D. J. Teece (1982a). "Supplier Switching Costs and Vertical Integration in the Automobile Industry.” Bell Journal of Economics 13: 206-213.

Monteverde, K. and D. J. Teece (1982b). “Appropriable Rents and Quasi-Vertical Integration.” Journal of Law and Economics 25(321-28).

Montignola, G., Y. Qian and B. Weingast (1993). Federalism Chinese Style.

Murray, J. Y. (2001). "Strategic Alliance-Based Global Sourcing Strategy for Competitive Advantage." Journal of International Marketing 9(4): 30-58.

Murray, J. Y. and M. Kotabe (1999). “Sourcing Strategies of U.S. Service Companies: A Modified Transaction-Cost Analysis.” Strategic Management Journal 20: 791-809.

Murtha, T. P. (1991). “Surviving Industrial Targeting: State Credibility and Public Policy Competencies in Multinational Subcontracting.” Journal of Law, Economics and Organization 7: 117-143.

Murtha, T. P. (1993). “Credible Enticements: Can Host Governments Tailor Multinational Firms' Organizations to Suit National Objectives?” Journal of Economic Behavior and Organization 20: 171-86.

Nee, V. (1992). “Organizational Dynamics of Market Transition: Hybrid Forms, Property Rights, and Mixed Economy in China.” Administrative Science Quarterly 37: 1-27.

Nelson, M. (1997). “Municipal Government Approaches to Service Delivery: An Analysis From a Transactions Cost Perspective.” Economic Inquiry 35(1): 82-96. 
Ngwenyama, O. K. and N. Bryson (1999). "Making the Information Systems Outsourcing Decision: A Transaction Cost Approach to Analyzing Outsourcing Decision Problems.” European Journal of Operational Research 115(351-367).

Nickerson, J. A., B. H. Hamilton and T. Wada (2001). “Market Position, Resource Profile and Governance: Integrating Porter and Williamson in the Context of International Courier and Small Package Services in Japan.” Strategic Management Journal 22(3).

Nickerson, J. A. and B. Silverman (1999). "Why Aren't All Truck Drivers Owner-Operators? Asset Ownership and the Employment Relation in Interstate For-Hire Trucking." Journal of Economics and Management Strategy 12(1): 91-118.

Nickerson, J. A. and R. Vanden Bergh (2001). “Economizing in the Context of Strategizing: Governance Mode Choice in Cournot Competition.” Journal of Economic Behavior and Organization 40: 1-15.

Noordewier, T. G., G. John and J. R. Nevin (1990). "Performance Outcomes of Purchasing Arrangement in Industrial Buy-Vendor Relationships.” Journal of Marketing 54: 80-93.

North, D. (1990). Institutions, Institutional Change, and Economic Performance. New York, Cambridge University Press.

Ohanian, N. K. (1994). “Vertical Integration in the U.S. Pulp and Paper Industry 1900-1940.” Review of Economics and Statistics 76(1): 202-207.

Osborn, R. N. and C. C. Baughn (1990). “Forms of Interorganizational Governance for Multinational Alliances.” Academy of Management Journal 33(3): 503-19.

Oxley, J. E. (1997). “Appropriability Hazards and Governance in Strategic Alliances: A Transaction Cost Approach.” Journal of Law, Economics and Organization 13(2): 387409.

Oxley, J. E. (1999). “Institutional Environment and the Mechanisms of Governance: The Impact of Intellectual Property Protection on the Structure of Inter-Firm Alliances.” Journal of Economic Behavior and Organization 28: 283-309. 
Palay, T. (1984). “Comparative Institutional Economics: The Governance of Rail Freight Contracting.” Journal of Legal Studies 13((June)): 265-88.

Palay, T. M. (1985). “Avoiding Regulatory Constraints: Contracting Safeguards and the Role of Informal Agreements.” Journal of Law, Economics and Organization 1: 155-76.

Park, S. H. and M. V. Russo (1996). "When Competition Eclipses Cooperation: An Event History Analysis of Joint Venture Failure.” Management Science 42(6): 875-890.

Pelletier-Fleury, N., Valerie Fargeon, Jean-Luis Lanoe and M. Fardeau (1997). “Transaction Costs Economics as a Conceptual Framework for the Analysis of Barriers to the Diffusion of Telemedicine.” Health Policy 42: 1-14.

Peltzman, S. (1991). “The Handbook of Industrial Organization: A Review Article.” Journal of Political Economy 99: 201-217.

Penrose, E. T. (1959). The Theory of the Growth of the Firm. Oxford, Basil Blackwell.

Perry, R. L. and J. D. Robertson (1998). “Political Markets, Bond Markets and the Effects of Uncertainty: A Cross National Analysis.” International Studies Quarterly 42: 131-160.

Phillips, L. T. (1991). “Contractual Relationships in the Deregulated Transportation Marketplace.” Journal of Law and Economics 34(2): 535-64.

Pilling, B. K., L. A. Crosby and D. W. Jackson (1994). “Relational Bonds in Industrial Exchange: An Experimental Test of the Transaction Cost Economics Framework.” Journal of Business Research 30(July): 237-51.

Pirrong, S. C. (1993). “Contracting Practices in Bulk Shipping Markets: A Transaction Cost Explanation.” Journal of Law and Economics 36(937-76).

Pisano, G. (1990a). “The Governance of Innovation: Vertical Integration and Collaborative Arrangements in the Biotechnology Industry.” Research Policy 20: 237-249.

Pisano, G. (1990b). “The R\&D Boundaries of the Firm: An Empirical Analysis.” Administrative Science Quarterly 35(1): 153-176. 
Poppo, L. and T. Zenger (1998). “Testing Alternative Theories of the Firm: Transaction Cost, Knowledge-Based, and Measurement Explanations for Make-or-Buy Decisions in Information Services.” Strategic Management Journal 19: 853-877.

Prager, R. A. (1989). "Franchise Bidding for Natural Monopolies: The Case of Cable Television in Massachusetts.” Journal of Regulatory Economics 1(2): 115-32.

Prager, R. A. (1990). “Firm Behavior in Franchise Monopoly Markets.” RAND Journal of Economics 21: 211-225.

Purcell, W. D. (1990). “Economics of Consolidation in the Beef Sector: Research Challenges.” American Journal of Agricultural Economics 72: 1210-1218.

Purcell, W.D. and W.T. Hudson (2004). "Risk Sharing and Compensation Guides for Managers and Members of Vertical Beef Alliances." Review of Agricultural Economics 25(1): 4465.

Read, R. A. (1983). The Growth and Structure of Multinationals in the Banana Export Trade. The Growth of International Business. M. C. Casson: 180-213.

Regan, L. (1997). “Vertical Integration in the Property-Liability Insurance Industry: A Transaction Cost Approach.” The Journal of Risk and Insurance 64(1): 41-62.

Reuer, J.J. and A. Arino (2002). "Contractual Renegotiations in Strategic Alliances." Journal of Management 28(1): 47-68.

Rialp, A., C. Axinn and S. Thach. "Exploring Channel Internationalization Among Spanish Exporters." International Marketing Review 19(2): 133-155.

Richman, B. D. (2006). "How Communities Create Economic Advantage: Jewish Diamond Merchants in New York." Law and Social Inquiry 31(2).

Richman, B. D. and C. Boerner (2006). "A Transaction Cost Economizing Approach to Regulation: Understanding the NIMBY Problem and Improving Regulatory Responses." Yale Journal on Regulation 23(1): 29-76. 
Rindfleisch, A. and J. B. Heide (1997). “Transaction Cost Analysis: Past, Present and Future Applications.” Journal of Marketing 61(4): 30-55.

Riordan, M. H. and O. E. Williamson (1985). “Asset Specificity and Economic Organization.” International Journal of Industrial Organization 3: 365-378.

Robertson, T. S. and H. Gatignon (1998). “Technology Development Mode: A Transaction Cost Conceptualization.” Strategic Management Journal 19(6): 515-531.

Robinson, J. and L. Casalino (1996). "Vertical Integration and Organizational Networks in California Medical Care.” Health Affairs 15: 7-22.

Saalfeld, T. (2000). "Members of Parliament and Government in Western Europe: Agency Relations and Problems of Oversight." European Journal of Political Research 37(3): 353-376.

Sampson, R.C. (2004). "The Cost of Misaligned Governance in R\&D Alliances." Journal of Law, Economics, and Organization 20(2): 484-526.

Sampson, R. C. (2006). “R\&D Alliances \& Firm Performance: The Impact of Technological Diversity and Alliance Organization on Innovation.” Academy of Management Journal.

Saussier, S. (2000). “Transaction Costs and Contractual Incompleteness: The Case of Electricite de France.” Journal of Economic Behavior and Organization 42: 189-206.

Shapiro, S. P. (1987). “The Social Control of Impersonal Trust.” American Journal of Sociology 93(November): 623-658.

Shelanski, H. A. (2004). “Transaction-Level Determinants of Transfer Pricing Policy: Evidence from the High-Technology Sector.” Industrial and Corporate Change 13(6): 953-966.

Shelanski, H. A. and P. G. Klein (1995). “Empirical Research in Transaction Cost Economics.” Journal of Law, Economics, and Organization 11.

Shirley, M. and C. Xu (1998). "Information, incentives, and commitment: An Empirical Analysis of contracts between Government and State Enterprises.” Journal of Law, Economics and Organization 14(12): 358-378. 
Silverman, B. (1999). “Technological Resources and the Direction of Corporate Diversification: Toward an Integration of the Resource-Based View and Transaction Cost Economics.” Management Science 45(8): 1109-1124.

Silverman, B. S., J. A. Nickerson and J. Freeman (1997). "Profitability, Transactional Alignment, and Organizational Mortality in the U.S. Trucking Industry.” Strategic Management Journal 18(Summer Special Issue): 31-52.

Simon, H. (1957). Administrative Behavior ( $2^{\text {nd }}$ ed). New York, The Free Press.

Simonin, B. L. (1999). “Transfer of Marketing Know-How in International Strategic Alliance: An Empirical Investigation of the Role and Antecedents of Knowledge Ambiguity.” Journal of International Business Studies 30(3): 463-490.

Slater, G. and D. A. Spencer (2000). “The Uncertain Foundations of Transaction Cost Economics.” Journal of Economic Issues 34(1): 61-87.

Spiller, P. (1985). “On Vertical Mergers.” Journal of Law, Economics and Organization 1: 285312.

Spiller, P.T. and M. Tommasi (2003). "The Institutional Foundations of Public Policy: A Transactions Approach with Application to Argentina." Journal of Law, Economics, and Organization 19(2): 281-306.

Spiller, P. T. and I. Vogelsang (1994). Regulation, Institutions and Commitment in the British Telecommunications Sector. Washington, DC, World Bank.

Spiller, P. T. and B. A. Zelner (1997). "Product Complementarities, Capabilities and Governance: A Dynamic Transaction Cost Perspective.” Industrial and Corporate Change 6(3): 561594.

Stuckey, J. (1983). Vertical Integration and Joint Ventures in the Aluminum Industry. Cambridge, Harvard University Press.

Stump, R. L. and J. B. Heide (1996). “Controlling Supplier Opportunism in Industrial Relationships.” Journal of Marketing Research 33(November): 431. 
Sutcliffe, K. M. and A. Zaheer (1998). "Uncertainty in the Transaction Environment: An Empirical Test.” Strategic Management Journal 19: 1-23.

Taylor, C. R., Shaoming Zou and G. E. Osland (1998). “A Transaction Cost Perspective on Foreign Market Entry Strategies of US and Japanese Firms.” Thunderbird International Business Review 40(4): 389-412.

Teece, D. (1980). “Economies of Scope and the Scope of the Enterprise.” Journal of Economic Behavior and Organization 1: 223-247.

Teece, D. J. (1986). “Profiting from Technological Innovation: Implications for Integration, Collaboration, Licensing and Public Policy.” Research Policy 15(December): 285-305.

Troesken, W. (1997). “The Sources of Public Ownership: Historical Evidence From the Gas Industry.” Journal of Law, Economics and Organization 13(1): 1-25.

Ulset, S. (1996). "R\&D Outsourcing and Contractual Governance: An Empirical Study of Commercial R\&D Projects.” Journal of Economic Behavior and Organization 30(1): 6382.

Van Huylenbroeck, G., W. Verbeke, and L. Lauwers (eds.) (2004). Role of Institutions in Rural Policies and Agricultural Markets (Elsevier).

Vatn, A. (1998). “Input Versus Emission Taxes: Environmental Taxes in a Mass Balance and Transaction Costs Perspective.” Land Economics 74(4): 514-25.

Verrnimmen, T., W. Verbeke, and G. van Huylenbroeck. "Transaction Cost Analysis of Outsourcing Farm Administration by Belgian Farmers." European Review of Agriculture Economics 27(3): 325-45.

Villalonga, B. and A. McGahan (2001). "How Much does Governance Form Matter? Evidence from Stock Market Reactions to Acquisitions and Alliances.” Boston University School of Management mimeo: 1-28.

Walker, G. and D. Weber (1984). “A Transaction Cost Approach to Make-or-Buy Decisions.” Administrative Science Quarterly 29: 373-91. 
Walker, G. and D. Weber (1987). “Supplier Competition, Uncertainty and Make-or-Buy Decisions.” Academy of Management Journal 30(589-96).

Warfield, T. D., J. J. Wild and K. L. Wild (1995). "Managerial Ownership, Accounting Choices, and Informativeness of Earnings.” Journal of Accounting and Economics 20(1): 61-91.

Wathne, K. H. and J. B. Heide (2000). “Opportunism in interfirm relationships: Forms, outcomes, and solutions.” Journal of Marketing 64(4): 36-51.

Weingast, B. (1995). “The Economic Role of Political Institutions: Market-Preserving Federalism and Economic Development.” Journal of Law, Economics and Organization 11: 1-31.

Weingast, B. and W. J. Marshall (1988). “The Industrial Organization of Congress; or, Why Legislators, like Firms are not Organized as Markets.” Journal of Political Economy 96(1): 132-163.

Weiss, A. M. and E. Anderson (1992). “Converting from Independent to Employee Salesforces: The Role of Perceived Switching Costs.” Journal of Marketing Research 29(February): 101-15.

Weiss, A. M. and N. Kurland (1997). "Holding distribution channel relationships together: The role of transaction-specific assets and length of prior relationships.” Organization Science 8(6): 612-623.

Whinston, M. D. (2001). “On the Transaction Cost Determinants of Vertical Integration.” Northwestern University Working Paper.

Wielhouwer, P. (1994). Mobilizing Political Participation: Political Parties as Transaction Cost Minimizers. Political Science. Athens, GA, University of Georgia.

Williamson, O. E. (1964). The Economics of Discretionary Behavior: Managerial Objectives in a Theory of the Firm. Englewood Cliffs, NJ, Prentice-Hall.

Williamson, O. E. (1975). Markets and Hierarchies: Analysis and Antitrust Implications. New York, The Free Press. 
Williamson, O. E. (1976). “Franchise Bidding with Respect to CATV and in General.” Bell Journal of Economics 7(1): 73-104.

Williamson, O. E. (1979). “Transaction-Cost Economics: The Governance of Contractual Relations.” Journal of Law and Economics 22(October): 233-261.

Williamson, O. E. (1981). “The Economics of Institutions: The Transaction Cost Approach.”. Williamson, O. E. (1985). The Economic Institutions of Capitalism. New York, NY, The Free Press.

Williamson, O. E. (1988). “Corporate Finance and Corporate Governance.” Journal of Finance(July): 567-91.

Williamson, O. E. (1991). “Comparative Economic Organization: The Analysis of Discrete Structural Alternatives.” Administrative Science Quarterly 36(June): 269-296.

Williamson, O. E. (1996). The Mechanisms of Governance. New York, NY, Oxford University Press.

Williamson, O. E. (1998). “Transaction Cost Economics: How it Works; Where it is Headed.” De Economist 146(1): 23-58.

Williamson, O. E. (1999). Strategy Research: Governance and Competence Perspectives. Berkeley, CA, Business and Public Policy.

Williamson, O. E. (2000). “The New Institutional Economics: Taking Stock, Looking Ahead.” Journal of Economic Literature 38: 595-613.

Williamson, O. E. (2001). “The Theory of the Firm as Governance Structure.” University of California at Berkeley Working Paper.

Woodward, S. (1988). “A Transaction Cost Analysis of Banking Activity and Deposit Insurance.” Cato Journal 4(3): 683-699.

Zaheer, A., B. McEvily and V. Perrone (1998). "Does Trust Matter? Exploring the Effects of Interorganizational and Interpersonal Trust on Performance.” Organization Science 9(2): 141-159. 
Zaheer, A. and N. Venkatraman (1995). “Relational Governance as an Interorganizational Strategy: An Empirical Test of the Role of Trust in Economic Exchange.” Strategic Management Journal 16: 373-392.

Zhao, H., Y. Luo, and T. Suh (2004). "Transaction Cost Determinants and Ownership-Based Entry Mode Choice." Journal of International Business Studies 35(6): 524-544.

Ziedonis, R.H. (2004). "Don't Fence Me In: Fragmented Markets for Technology and the Patent Acquisition Strategies of Firms." Management Science 50(6): 804-820.

Zinn, J.S., V. Mor, O. Intrator, Z.L. Feng, J. Angelelli, and J.A. Davis (2003). "The Impact of the Prospective Payment System for Skilled Nursing Facilities on Therapy Service Provision: A Transaction Cost Approach." Health Services Research 38(6): 1467-85.

Zupan, M. A. (1989). “Cable Franchise Renewals: Do Incumbent Firms Behave Opportunistically?” RAND Journal of Economics 20(4): 473-482.

Zupan, M. A. (1989). “The Efficacy of Franchise Bidding Schemes in the Case of Cable Television: Some Systematic Evidence.” Journal of Law and Economics 32(October): 401-456.

Zylbersztajn, D. and S.G. Lazzarini (2005). "On the Survival of Contracts: Assessing the Stability of Technology Licensing Agreements in the Brazilian Seed Industry." Journal of Economic Behavior and Organization 56(1): 103. 
Figure 1: Cumulative and Yearly Empirical TCE Articles (Overall)

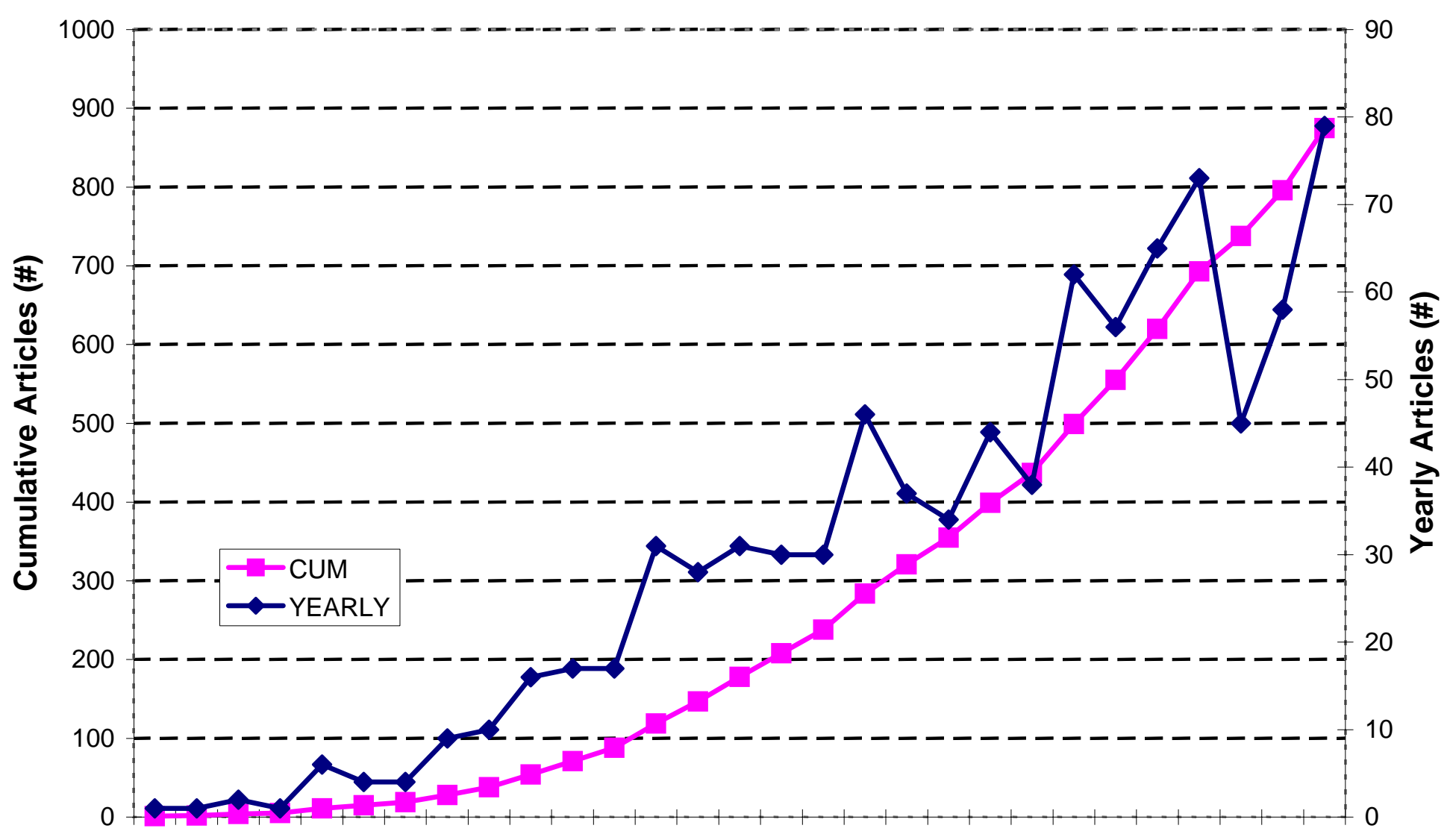

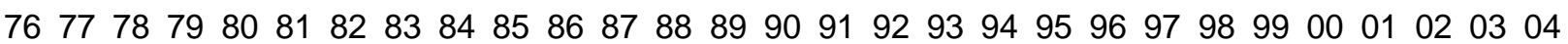

Year 
Figure 2: Cumulative Empirical TCE Articles (by Area)

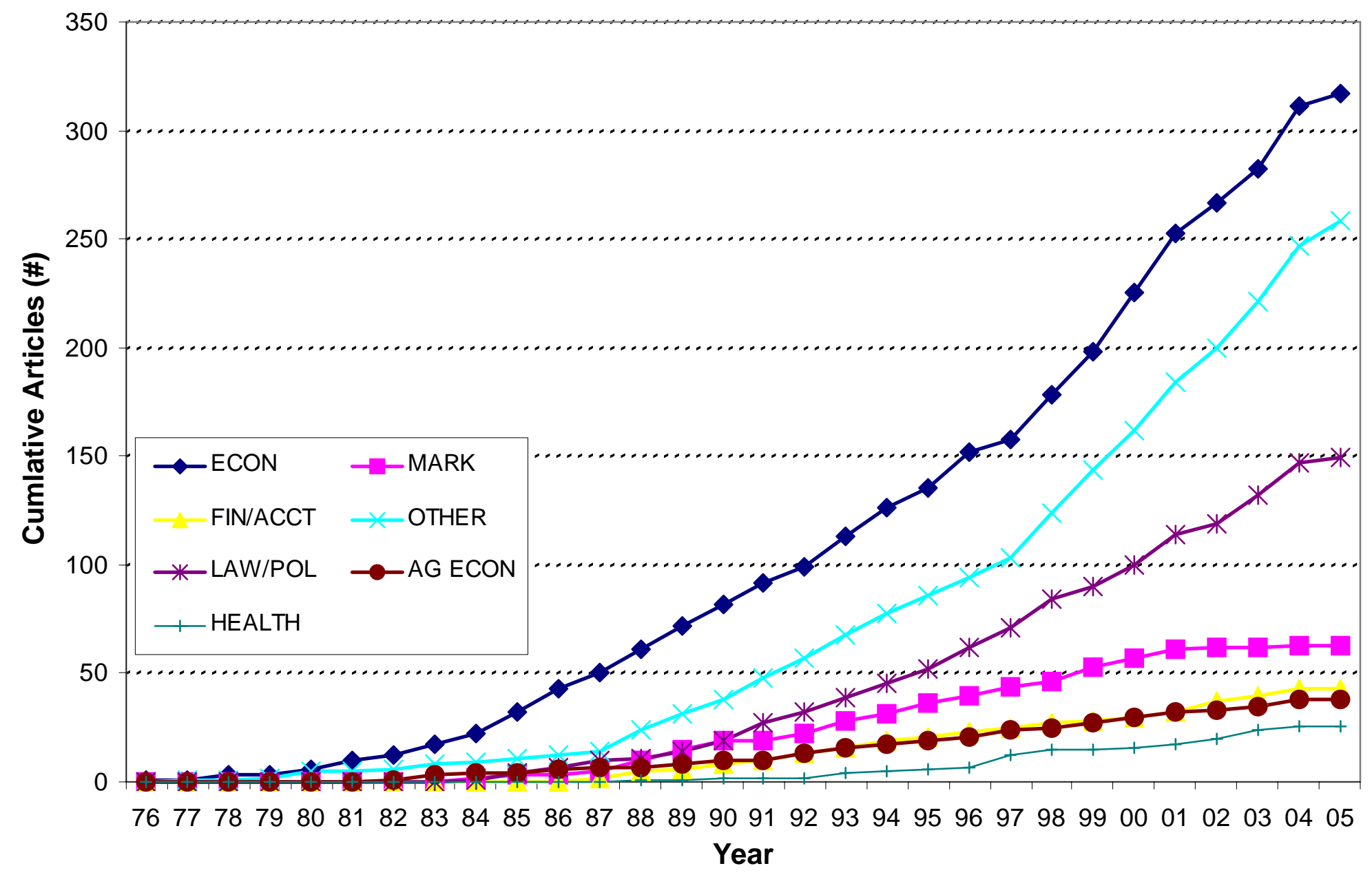

Note: Other Business includes Business History, Innovation, International Business, and Organizational Behavior 